\title{
"YOU TOLD ME WHEN IT WAS TOO LATE": AN AUTOETHNOGRAPHIC REFLECTION ON (NOT) KNOWING AND BEREAVEMENT
}

by

Nicole Ashley Dulysh, B.ASc ECS, RECE. Guelph- Humber University, 2016

\author{
An MRP \\ presented to Ryerson University \\ in partial fulfillment of the \\ requirements for the degree of \\ Master of Arts \\ in the Program of \\ Early Childhood Studies
}

Toronto, Ontario, Canada, 2019

(C) Nicole Dulysh 2019 


\section{AUTHOR'S DECLARATION FOR ELECTRONIC SUBMISSION OF A MRP}

I hereby declare that I am the sole author of this MRP. This is a true copy of the MRP, including any required final revisions.

I authorize Ryerson University to lend this MRP to other institutions or individuals for the purpose of scholarly research

I further authorize Ryerson University to reproduce this MRP by photocopying or by other means, in total or in part, at the request of other institutions or individuals for the purpose of scholarly research.

I understand that my MRP may be made electronically available to the public. 


\begin{abstract}
"You told me it was too late": An autoethnographic reflection on (not) knowing and bereavement Master of Arts, 2019

Nicole Dulysh

Program of Early Childhood Studies,

Ryerson University
\end{abstract}

A parent diagnosed with terminal cancer is focused on their own struggle with life and death.

They often do not have the mental capacity to think rationally about what is in the best interest of their child at this time. Without a doubt, the grieving process of a child ${ }^{1}$ who is informed about their parent's diagnosis will have a different experience than a child who is not informed. Following on an autoethnographic approach I will revisit my past experience of my mom's diagnosis with lung cancer and my father's diagnosis of a cancerous tumor on his vocal cords as I share, explore, and reflect upon my involvement in both matters. These experiences will be shared along with the six stages of grief by Elisabeth Kübler-Ross and David Kessler as I provide a deeper understanding of how a child being informed or uninformed throughout the diagnosis can impact their feelings of guilt and sorrows leading up to death.

Keywords:

Palliative care, Cancer, Children, Parental Cancer, Communication, Relationship, Behaviour

\footnotetext{
${ }^{1}$ Throughout this MRP, I use the term child or children as inclusive of children and youth
} 


\section{ACKNOWLEDGEMENTS}

I would like to thank my supervisor, Dr. Susan Jagger, for her continuous support and inspiration throughout this Master's Research Paper. You encouraged me to think about my experience and life in various views making the process rewarding. With the endless knowledge you provided me, I am completely humbled at the amount of time and energy you helped me put into this research. I would also like to thank Dr. Aurelia Di Santo and her class "Children's Rights" for helping me find my passion for educating children about their rights in an effort to help them fight for what they believe is in their best interest. Your passion and dedication for inspiring young adults has allowed me to develop a fight for children and their right to be involved in decisions involving them.

My Dad and Sister, I am forever grateful for your continuous support throughout this process. You both have helped me through long nights and stressful times. Without you both believing in me, I wouldn't have been able to get through the program. Kristen, you are my role model, I am forever grateful for the strength you continuously show me, and the continuous support you provide me. Additionally, I would like to thank my boyfriend Cody, your continuous support and love has allowed me to get through challenging, hard, and tearful nights. I couldn't have completed this work without you providing memories and humour to my long nights of recalling sad, traumatic, and emotional memories. I also wouldn't have been able to survive the last few years of my life without you by my side. 
Lastly, to my sister's boyfriend and the Patro family, thank you for allowing me to take my anger and frustration out on you continuously, and always supporting my decisions and learning. You welcoming me into the family has provided me with immense love and continuous happiness. To my best friend, Kristen, you have provided me with a shoulder to cry on and were on-call every step of my journey, your encouragement and friendship will never go unnoticed. Thank you for believing in me when I didn't believe in myself, and never turning your back when times get tough.

Finally, to all my friends and family, your continuous support allowed me to keep going, from the campfires to long nights writing outside. You provided me with times for laugher and times for silence. 


\section{DEDICATION}

I dedicate this work to Cindy Dulysh, not only my mom but a hero that left me too soon. Although you're gone, you continuously inspire me to inspire others.

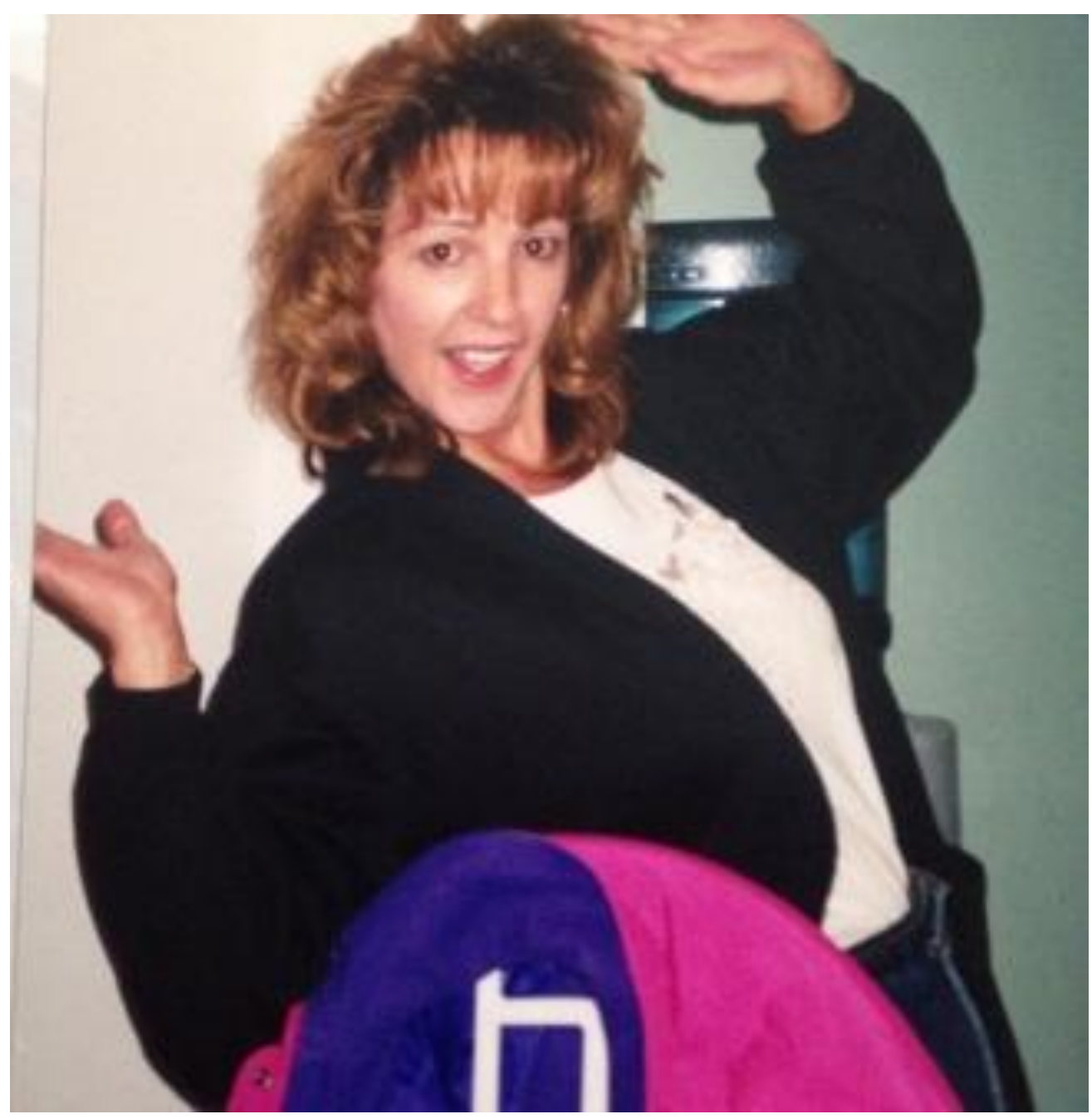




\section{TABLE OF CONTENTS}

Stages of Grief: Introduction

Page 1

Denial: The Process

Page 4

Qualitative Autoethnographic Research

Page 4

Ecological Systems and Attachment Theories

Page 7

Situating Myself in the Research

Page 10

Research Design and Representation

Page 11

Anger: Pre-Diagnosis

Page 15

September 8, 2009

Page 15

January 10, 2010

Page 18

April 23, 2010

Page 20

June 14, 2010

Page 28

Bargaining: Treatment

Page 32

July 13, 2010

Page 32

July 19, 2010

Page 37

April 22, 2011

Page 40

January 14, 2013

Page 42

March 21, 2013

Page 44

April 29, 2013

Page 47

June 24, 2015

Page 49

December 4, 2015

Page 51

February 5, 2016

Page 51

February 7, 2016

Page 53 
Depression: Loss of Mom

Page 58

February 7, 2016

Page 58

February 8, 2016

Page 59

February 10, 2016

Page 63

March 1, 2016

Page 64

April 3, 2016

Page 66

Acceptance: Dad's Health

Page 68

April 24, 2016

Page 68

May 5, 2016

Page 69

June 11, 2016

Page 71

October 8, 2016

Page 72

January 29, 2017

Page 73

Finding Meaning: Conclusion

Page 75

August 10, 2019

Page 75

Appendices

Page 86

Appendix A: Consent Form

Page 86

Appendix B: Ethics Approval

Page 90

Appendix C: Ethics Certificate

Page 92

References

Page 93 


\section{LIST OF ILLUSTRATIONS}

Figure 1: Mom and me

Page 16

Figure 2: Mom

Page 45

Figure 3: Funeral

Page 64

Figure 4: Lady Bug Tattoo

Page 77

Figure 5: For You Cindy

Page 84 


\section{APPENDIX}

Appendix A: Consent Form

Page 86

Appendix B: Ethics Approval

Page 90

Appendix C: Ethics Certificate

Page 92 


\section{Stages of Grief: Introduction}

\section{There is not a typical response to loss as there is no typical loss.}

(Kübler-Ross \& Kessler, 2005)

Elisabeth Kübler-Ross (2005) identified five stages of grief, describing them as a framework to support our living with and learning about living with loss when experiencing death (Kübler-Ross \& Kessler, 2005). However, it is stressed that these stages do not happen in a prescribed order, and some individuals may not experience all stages. Instead, the stages can be used to help one become better equipped to experience loss and continue with their life. David Kessler, a researcher of grief and loss, co-wrote several books with Kübler-Ross, and eventually identified a sixth stage: finding meaning (Kübler-Ross \& Kessler, 2005). While individuals experiencing loss may not go through all stages, finding meaning is important for those grieving and has been especially significant in my own grief process.

My mom battled lung cancer for five years, but in the last seconds of her life, it felt like she flashed before my eyes. One might argue that I had time to prepare, but I would counter that there is no amount of time that can ready you for the loss of a parent. Unfortunately, through my mother's battle, decisions had to be made and since I was young, my parents used silence as safety, and protected me from the inevitable.

A parent diagnosed with terminal cancer is focused on their own struggle with life and death. They often do not have the mental capacity to think rationally about what is in the best 
interest of their child at this time. Guidance from medical professionals and social workers can better equip parents to make rational decisions about their children's knowledge of and involvement in their parent's illness and provide the child with emotional support during this difficult time. However, the use of these resources requires the child to be aware of their parent's terminal diagnosis. Without a doubt, the grieving process of a child who is informed about their parent's diagnosis before death will be a different experience than a child who is not informed of their parent's diagnosis. Grief refers to "distress resulting from the loss and includes mental, physical, social, or emotional difficulties" (Johnson, Torres, Sykes, Gibson, \& Baker, 2017, pg. 2). On the other hand, bereavement referrers to bereavement is "the objective situation of losing someone significant through death and the adjustments that follow" (Johnson, Torres, Sykes, Gibson, \& Baker, 2017, p. 2).

There has been considerable research conducted to illuminate motivations behind a parent's decision to inform or not inform their child of their diagnosis (Finch \& Gibson, 2009; Fearnley, 2010, 2012; MacPherson, 2015, 2018). Christ (2000) and Harris (2003) are two of many who have outlined the benefits and negative consequences of informing a child about a parent's terminal illness of cancer. There has been research being done on why a parent may choose to inform their child (Christ, 2000; Harris, 2003), why it might be beneficial to keep your child uninformed throughout the process, and the problems that may arise after death (Fearnley, 2010, 2012; Finch \& Gibson, 2009; Rosenheim \& Reicher, 1985). However, there is very little information on a child's opinion of whether they should be informed about the diagnosis (Leedham \& Meyerowitz, 1999; McPhail, Dwyer, Hanemaayer, Preyde, 2017). Similarly, there is limited research on the impact of being informed or uninformed about the terminal illness during the diagnosis leading to death through the eyes of the child (Buchwald, Delmar, \& 
Schantz-Laursen, 2012). Further research is required to determine how being informed or uninformed about a parent's terminal diagnosis impacts the child's grieving process throughout the experience.

This study seeks to better understand a child's perspective on being, and not being, informed during the terminal illness of their parent, and how this information, or lack of information, supported their bereavement after their parent's death. However, my perspective is written as an adult reflecting back on their childhood experience. Drawing from my own memories and reflecting on my own experiences, I detail important touchstones through the diagnosis period of my mother's and father's illnesses in order to identify the positive outcomes that information can lead to. Furthermore, I discuss the power struggle and shifts in our family dynamics associated with cancer diagnosis and treatment, and its impact on the child over time in my personal narrative. 


\section{Denial: The Process}

\section{Your grief is just as unique as you are.}

(Kübler-Ross \& Kessler, 2005)

Denial is not defined as a misbelief that your loved one has passed away, but as the overwhelming feelings of numbness and shock as this reality was never expected (Kübler-Ross \& Kessler, 2005). Elisabeth Kübler-Ross and David Kessler (2005) describe it as "you come home, and you can't believe your wife isn't going to walk in the door at any minute or can't believe that your husband isn't on a business trip. You simply can't fathom that he will never walk through those doors again” (pg. 8). Denials allow individuals to survive the loss, it gives the loved one hope that they will return, taking away their pain for brief minutes (Kübler-Ross \& Kessler, 2005). Denial often takes the form of questions, questioning their new reality, is this real? Unknowingly beginning the healing process and denial begins to fade (Kübler-Ross \& Kessler, 2005).

\section{Qualitative Autoethnographic Research}

Individuals are understandably under an immense amount of stress when dealing with their diagnosis of a terminal illness. Decisions need to be made, lifestyles are being changed, and identities change along the diagnosis and treatment journey. This stress is intensified if the individual is also a parent. What should their child know? How much should they know? Or, is it better for them to not know? Examining a child's role in the terminal illness journey of a parent can help to illuminate some potential answers to these questions and using a qualitative research approach to explore this role can weave the child and parent's experiences, understandings, and 
reasonings throughout shared narratives (Leavy, 2017). Qualitative research can provide insight and understanding of people's experiences thus enabling the reader to better understand actions associated to circumstances (Denny \& Weckesser, 2019). As Flick (2007) describes, qualitative research uses "text as empirical material" and is interested in the "perspective of participants in everyday practices and knowledge referring to the issue under study" (p. 2). This approach to studying experience, phenomena, and relationships allows individuals to understand things in their natural setting, attempting to make sense of it, and interpret the phenomena or human behaviour (Flick, 2007). Qualitative research often involves interviews or participant observations as a form of data collection (Leavy, 2017). This can be done through journaling and story-telling as the participant relates to aspects of their lives relevant to the research. Through descriptive language, emotions are brought into context and analysis of the material is conducted to make meaning of phenomena.

Research methods are put into place to explore and answer questions posed in the research purpose and provide a theoretical framework for the study. In the study of children being informed (and not informed) of parental illness, the researcher must be particularly aware of the impact of their examination on potential participants, both children and adults. Due to the liability associated with doing research with children, it was important for me to not add stress or upset participants or make it more difficult for the healthy parent to care for their child if asked to recall the event of the deceased parent. Sharing memories of their family and deceased family member can be difficult for an adult, and even more so for a child. For that reason, I decided to follow an autoethnographic approach and use my own personal experiences to guide my exploration of children's knowledge, understanding, and participation in their parent's terminal illness. 
Studies of oneself, or autoethnographies, are guided by ethnomethodology's, "social theor[ies] that look at how social order is possible" (Trace, 2016, p. 48). They draw on specific strategies that people use to provide meaning to their interactions (Leavy, 2017) and view humans as agents of their lives, analyzing their interactions and experiences to find a conclusion or answer their question (Trace, 2016). An autoethnography is an "alternative method of writing" (Denshire, 2014, p. 1) that seeks to analyze personal experiences in order to understand cultural experience (Ellis, Adams, \& Bochner, 2011). Autoethnographies draw from self-data, or data from the researcher herself, and depend on "the researcher viewing themselves as a knowing subject" (Leavy, 2017, p. 144). In other words, the research values the researcher's personal experiences. This type of research can only be conducted if the researcher is willing to be completely open and transparent about their personal experience regardless of how uncomfortable and stressful it may be for the researcher to do so. Also, this method can only be used if the researcher has personal experience with the topic under investigation and is willing to relate those personal experiences. In this study, an autoethnographic approach allows me to share my complex stories and life experiences and create meaning based on a phenomenon while incorporating feelings and struggles (Ellis, Adams, \& Bochner, 2011). This research is also reflective of the relationships built within the family structure and the impact change can take on an individual experiencing loss.

Memory is a powerful tool as it provides individuals the ability to store, retain, and recall information and past experiences. When using memory to recall situations and circumstances it is not perfect nor representative of the whole truth, but rather it allows one to share their story in a “neat package” (Adams, Bochner, \& Ellis, 2011, p. 9). Memory allows one to frame experiences with a beginning, middle, and end with no outliers to make the story seem spotless. 
Autoethnographic research acknowledges the challenge in using memory to recall past experiences, and know it is impossible to "recall or report on events in language that exactly represents how those events were lives and felt" (Adams, Bochner, \& Ellis, 2011, p.9). The experiences shared in this research are true and have allowed me to make meaning of significant events in my life. However, this research is based on my recollection of past experiences that I had from the age of twelve to now. I am aware that my memories are inherently selective and I am also aware that I am recalling my experience of my parents' cancer diagnoses now as an adult.

Evident throughout the research is the relationships created between my family, professionals, and friends as we experience a life changing event. The relationships I have with my sister, parents, boyfriend, and medical professionals illustrate the strong bond created in order to handle the emotions and changes and feel safe. It is clear that the relationships I have within my family, and the attachment and security my parents built with me from birth, impact my experience. Using both the ecological systems theory and attachment theory, I illustrate the impact that social interactions and relationships had throughout my experience.

\section{Ecological Systems and Attachment Theories}

Bronfenbrenner's ecological systems theory is the most adaptable theoretical framework used for research on individuals in their natural environments (Neal \& Neal, 2013). According to Bronfenbrenner, children are enmeshed in various systems, from the most intimate home ecological system to the larger school system (Neal \& Neal, 2013). Following, children will find themselves at the most expansive system which includes society and culture. Each of these ecological systems inevitably interact with and influence each other in all aspects of a child's life 
and at all times (Neal \& Neal, 2013). Bronfenbrenner identified levels of ecological systems which are interrelated and are set in structure centred on the microsystem (Neal \& Neal, 2013; Paat, 2013). This lowest level, the microsystem, reflects the impact that social interactions with parents, siblings, family, and friends can have on an individual (Neal \& Neal, 2013). Next, the mesosystem consists of the relationships between the individuals in the microsystem (Neal \& Neal, 2013; Paat, 2013). This level includes, for example, parent-teacher relationships. Here, a child misbehaving at school may be disciplined at home should parents be informed of the school occurrences and this may cause a change in behaviour. The exosystem extends beyond the mesosystem and here, policies and decisions are made that may not involve the individual but continue to affect them (Neal \& Neal, 2013; Paat, 2013). This can be illustrated as education policies put in place or a parent's career sending them abroad; both affect a child's experience without the child's direct involvement. Next, the macrosystem involves the cultural context that an individual lives within and its impact on their life (Neal \& Neal, 2013; Paat, 2013). The cultural context can include a family's socioeconomic status, race, or living conditions that might lead an individual to work longer or endure racism due to circumstances they cannot change. Finally, the chronosystem is the final level and it includes life transitions and the changes that an individual goes through over time, such as divorce (Paat, 2013). Each level of the ecological systems theory influences a child's development and social interactions. As a child faces events and challenges in their life, their relationships with family and friends can support them. Without a doubt, a child's bond with their parents can influence their relationships and, as Bronfenbrenner illustrates, can affect their experiences and relationships with others around them. 
Also relevant to my study of children's knowledge, understanding, and experience of a parent's terminal illness is attachment theory. Attachment theory plays a crucial role in understanding the connection between a parent and a child. John Bowlby developed attachment theory and examined the consequences of separation from a parent on a child's development (Bretherton, 1992). Attachment theory illustrates the child's prolonged attachment to parents throughout their lifespan, constantly changing their role of attachment in their child's life (Milberg and Friedrichsen, 2017). Attachment theory shows the various levels of connection a child has to their parents throughout their lifespan and highlights the dramatic effect that the death of a parent can have on their child's attachment security.

Using theory and writing, this study captures the emotions, feelings, stress, and pain felt by one child in their experience of parental illness and death. Using writing as a method allows the research to be authentic and descriptive. St. Pierre (2018) describes it as the start of deconstruction, "the movement of writing takes over, and the writer, the person loses control and finds themselves barely able to keep up in the thinking- writing as words appear on the computer screen they could not have thought without writing" (p. 605). The problem with structured methods-driven methodologies is the editing process that requires researchers to bound their data to ensure their research question is being answered (St. Pierre, 2018). However, often this involves discarding data which seems too strange to count as inquiry or as important to the research (St. Pierre, 2018). The data should include the too strange, the seemingly random information that provides context and substance to experiments and research; it takes research beyond what everyone already knows, the ordinary, and provides variation and imagination (St. Pierre, 2018). Writing is investigation, examination, and analysis, and it allows the research to 
invent and uninvent phenomena in the world through story sharing, lettering, and journaling (St. Pierre, 2018).

\section{Situating Myself in the Research}

I am inherently within this study as it recalls and reflects on my own experience of parental terminal illness and loss as a child from my perspective now as an adult. However, how does my educational background and practical experience guide my research? As the researcher, I have a background in applied science with a major in Early Childhood Studies from the University of Guelph- Humber. I am currently a Master of Arts student in the School of Early Childhood Studies at Ryerson University. My course experience has focused on children's health and well-being and I have extensive experience working with children across a range of settings. This research will be written using a children's rights lens, looking at relationship dynamics in a family setting.

The study shares and reflects upon my own experiences of grief and loss related to the cancer diagnoses of both my mother and father, and the impact of knowing and not knowing about the illnesses on my bereavement. Through revisiting through writing and reviewing the experiences, the positive and supportive ways of recognizing children's rights in this unique context of illness and following grief and realizing and enacting what might be best for the child are illuminated. Death is a subject that most people do not know how to deal with and are thus often left with unanswered questions. In their illness-related experiences and decision-making, parents are faced with situations where they may act on impulse, realizing after the fact that their actions may not have been in the best of their child or even their family as a whole. 
Using an autoethnographic approach informed by ecological systems and attachment theories, I am able to gain a clearer understanding of the decisions that take place during my mother and father's diagnosis through treatment and my mother's death to the following grief. Christ (2000) and Fearnley (2012) found that both parents feel they are protecting their children from the emotional pain by not informing them of illness. On the other hand, Harris (2003) and Finch and Gibson (2009) argued that when children are involved in the treatment process, the family experiences a greater quality of life and family bonding opportunities. An autoethnographic approach will guide my explorations of these divergent findings in relation to my own experiences with parental terminal diagnosis, family decisions, my involvement, and my bereavement after my mother's death. It situates my experience of the diagnosis up to the death of my parent in the literature, and my thoughts and feelings on what was most beneficial for my process and what might have been done differently through my own perspective.

\section{Research Design and Representation}

I am the sole direct participant in this study; data are comprised solely of my memories of first hand experiences and associated thoughts, feelings, and questions. These are written as my voice as an child going through those experiences. I asked my family members to consent to me conducting the explorations as they are evidently involved in these experiences and emotions. Although my participants provided permission for me to complete the research, they were not involved in my recollections of past events. For example, in my writing I did not talk together with my family members about when my mother was diagnosed with cancer and receiving treatment. Despite their distance from my data collection, there were still potential risk factors. One risk is the potential pressure to consent to the research due to the family relationship with 
me, the researcher. I mitigate this risk by checking regularly throughout my writing process about continuing consent and providing ample time to decline participation. Another risk is psychological risk including the possibility of discomfort or anxiety knowing that their family experiences are being shared and would be available through the Ryerson Library. Again, I had several conversations with family members to clarify and answer any questions about the research products. I also checked in with them regularly to ensure that they are still comfortable with me continuing with the research. I shared with family members drafts of my research paper so that they were aware of what was being written and had the opportunity to request changes. Finally, participant identity being revealed is a risk factor. The research does not include given names of my family members but does identify them as their family roles (i.e., dad, sister, etc.). For this reason, community members could identify them through their relation to me. This risk was explained in person and detailed on the consent form. I checked regularly during my writing that my family members were comfortable with this risk and gave them the opportunity to withdraw consent if they changed their minds. None of my family members withdrew consent to my conducting the study and there were no issues related to participation and consent.

The research is based on my memory of difficult times. It is therefore important to carefully document experiences, emotions, and questions. I used extensive note taking and journaling to write down my emotions and experiences and organize significant events into chronological order. As I recall my experiences, I am mindful of my recollection of events straying from the actual events due to the time that has passed between this period of my life and my writing of this research text. The notes and journal writing data were collated and categorized to ensure content was related to the topic and relevant to the study. Once the content was written, data analysis began as themes and meaningful interpretations from the written material are 
outlined. In order to gain a greater understanding of the data collected, I conducted all parts of data collection and analysis by hand; I did not use any analytic software or programs. The content remains true to my thoughts and feelings and was not be edited or beautified. The notes and data were saved to a portable USB with a locked password to access files.

Dominant themes that persisted throughout the data and memo notes were used to make meaning of the phenomena and identify connections, similarities, and patterns. This process allowed me to make sense of the data collected and analyze the coded themes to look for links between categories, concepts or themes (Leavy, 2017). In order to get a second review of the data collected, my Masters Research Paper supervisor reviewed the content and coding process to ensure that no material was misidentified or overlooked during categorization. This allowed me to be reflective of my own bias.

My representation of this paper is different from the traditional format of the thesis. My thoughts and feelings are identified through different fonts to show both emotion and control. Multiple reflective voices will be included in the narrative research text (e.g., my thoughts and memories) as the piece (re)presents the tensions, emotions, and questions of my journey with parental cancer victims and survivors. As my family sheltered me as I was growing up, perhaps to paint a perfect picture, many of the memories and emotions I recall are written in Century Gothic size 12. This font communicates perfect penmanship and illustrates how I felt my experience should be. Font size and character change throughout the paper to represent the emotions and their expression that I heard during my experience. While writing, there were excerpts that I took from letters written to my mom during hospital stays and visits and these are presented in Bradley Hand size 12 to show the close and personal nature of the exchanges. This font reminds me of writing quickly on a piece of paper, in a rush to finish on time. Most of 
my time with my mom was mediated by my parents, especially during her hospitalization. Therefore, the font shows uncertainty and stress. Next, Times New Roman size 12 font presents the connections and commonalities between the literature and themes identified in the research. Lastly, Comic Sans MS size 12 font presents my life now and the emotions and experiences I continue to face. This font reminds me of my own writing, as I write across a note book creating memories of my life experiences after the loss of my mom. As fonts and margins are interrupted throughout the paper, different voices and restraints felt throughout my experience are shown. My candid expression of experiences, emotions, and feelings invites the reader to empathize and make connections to their own experiences of illness, loss, and grief. Through various writing techniques I allow the reader to feel the emotion and struggle I experienced without them experiencing it themselves. As I continue to share my reflective narrative, the changing of fonts highlights the changing roles and shifting of power during difficult conversations and decisions. The fonts show these dynamic transitions from parental control and child participation to the child cast as adult and the change of family roles. As I continue to define my role and purpose in my crazy life, the changing of fonts represents my changing identity. 


\section{Anger: Pre-Diagnosis}

\section{The more you truly feel it, the more it will begin to dissipate and the more you will heal... The anger is just another indication of the intensity of your love.}

(Kübler-Ross \& Kessler, 2005)

Angry that the doctors were not able to save them, angry you were the one left behind, angry you were not given more time together (Kübler-Ross \& Kessler, 2005). Kübler-Ross and Kessler (2005) explain one will not reach this stage until they are able to feel safe and know they will be able to survive without their loved one. We often choose to avoid feelings of anger, but managing these feelings are a necessary step in order to heal and process grief (Kübler-Ross \& Kessler, 2005). Kübler-Ross and Kessler state "don't let anyone diminish the importance of feeling your anger fully" (p. 17); expressing your feelings of anger affirms you can feel, love, and have lost.

\section{September $8^{\text {th }}, 2009$}

Throughout my childhood, I was always anxious and would become overwhelmed by the normal stresses of daily life. I tried to accomplish too many things at once, and struggled to balance my responsibilities with school, friends, and family. Unlike me, my parents were always on top of everything. They arranged visits to the dentist and doctors. They shopped for clothes and food. They provided me with more than I could imagine. 


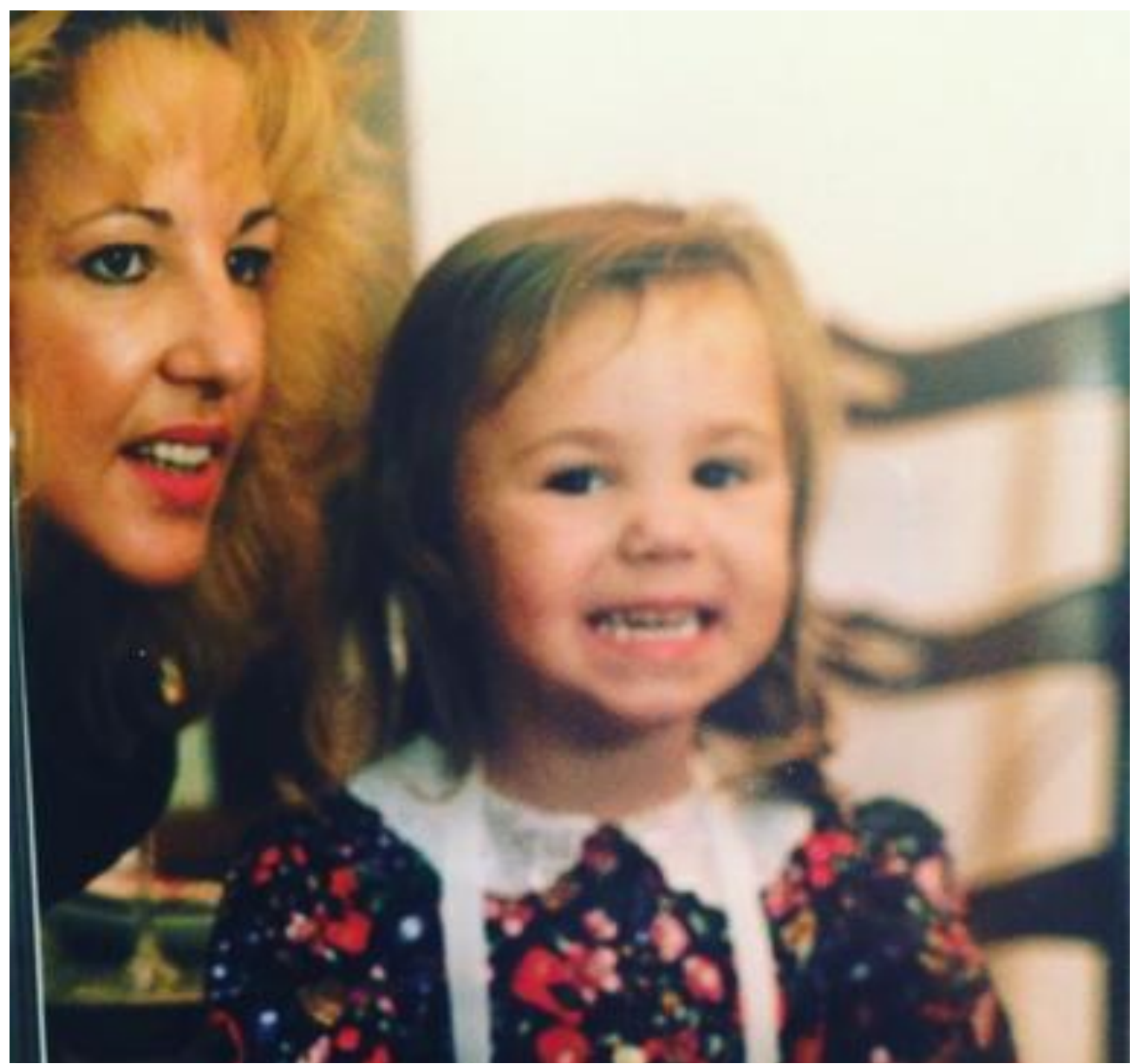

Figure 1: My mom and me.

When I was fourteen, I had my wisdom teeth extracted and my tonsils removed within two weeks of each other. Between the pain medication and not eating, I got sick. I came home from school one day, dizzy and vomiting. My stomach felt like it was on fire. My mom did what all moms would do - she booked a doctor's appointment.

When I was young, my mom came in the examination room with me during visits to the doctor. On this visit, the doctor diagnosed me with a stomach ulcer, prescribing me 5000 mg of antibiotics twice daily and a seemingly endless 
list of what I had to avoid eating. I laughed because I knew there was no way I would give up everything I loved to eat. My mom cleared her throat.

Parents are typically considered the primary caregivers of children and it has been widely agreed upon that parents are the most important people in a child's life (Board on Children, 2016). Bronfenbrenner's ecological systems theory identifies systems which impact a child's development and social interactions. As mentioned earlier, the lowest level reflects the impact social interactions with parents, siblings, family, and friends can have on an individual's development and relationships (Neal \& Neal, 2013; Patt, 2013). Without a doubt, a child's relationship with their parents influences their ability to create relationships with others around them (Neal \& Neal, 2013). I believe parents are considered primary caregivers making their child's development and needs their top priority. Conceptions of what raising a child looks like can vary across cultures and families, however the overall goal is to keep their child safe and prepare them for various environments leading to adulthood (Board on Children, 2016). Furthermore, experiences during early childhood can dramatically impact a child's well-being for future years. Nel Noddings developed one of the first theories of care, arguing that "caring is the foundation of morality" (Burton \& Dunn, 2017). Care is defined as "the provision of what is necessary for the health, welfare, maintenance, and protection of someone or something" (MerriamWebster, 2019). Caring involves a shift in relationship resulting in an interdependent partnership created between the two individuals (Stone, 2018). Previously stated, my parents cared for my sister and me by ensuring our health, 
safety, and well-being were at their highest priority. My parents put their

children's needs above their own, for instance, my mom taking me to the doctors for my illness before thinking of her health issues. Since we were young, they used to use say "it's our job, you are our children”, constantly providing for us even when we weren't able to provide for them. The carer acknowledges the best interest of the cared-for and acts based on their needs and wants, however, the carer does not provide for the other in search for a reward or praise (Stone, 2018). In terms of parents as their children's carers, developing a strong attachment with their children provides a solid foundation for healthy development (Board on Children, 2016). Growing up with the ability to speak to my parents regarding any problems allowed a healthy relationship to develop. For example, and as stated earlier, when I experienced stomach problems, I automatically approached my mom who acted instantaneously. Ideally, parents take up the carer role and think of their child's best interest before making decisions, and ensure that their health, safety, and development are prioritized.

\section{January 10,2010}

I remembered my mom having a sore throat for a little while at that point. When the doctor returned to us, I told my mom to mention it. We were already there so she might as well get antibiotics if she needed them. The doctor handed me my prescription and my mom told me to wait outside. The minutes of waiting felt like hours, but then she walked out, and we went home. I figured it was like any sore throat and that after some rest and fluids, life would go on. 
My sister and I would leave for school by 7:45am and my mom started work at 10am. My sister and I did not know it, but my mom had follow-up medical appointments booked. They were during the day and were kept a secret from us. We were at school so there was no way we would know. My dad was at home and would attend the appointments with her; he had been injured at work years before, so he was around.

It was unusual to arrive home from school and find my mom at home already. My mom was a workaholic and was always on the go. She worked as a waitress from approximately 10 a.m. to 9 p.m. during the week often on weekends too. A day off for my mom for no apparent reason was alarming. I felt that something was wrong, but I could not put my finger on it.

Children are accustomed to experiencing various routines throughout their day. They expect to complete certain tasks at certain times as they do so every day. Jenson, James, Boyce, and Hartnett (1983) define family routines as “observable, repetitive behaviours which involve two or more family members, and which occur with predictable regularity in the day-to-day and week-to-week life of the family" (p. 2001). My family had daily routines, we could expect dinner at the same time every day, weekends were for grocery shopping; any change in routine meant panic. My parents would take us out for dinner on all occasions, and worked the same shifts, as stated earlier, any changes were alarming. Research suggests that children's behaviour is disrupted when they experience a change in routines, often caused by economic hardship (Jenson, 
James, Boyce, \& Hartnett, 1983; Mistry, Vanderwater, Huston, \& McLoyd, 2002). Related, Budescu and Taylor (2013) note changes in routine and parental presence can result from a parent's stress from time off work and uncertainties about the future. Kitsaras, Goodwin, Allan, Kelly, and Pretty (2018) conducted a study on the impact that bedtime routines can have on a child's sleep patterns and cross-referenced that impact on their development. They found that regular and consistent routines resulted in children's better overall dental health, cognitive function, and school readiness (Kitsaras, Goodwin, Allan, Kelly, \& Pretty, 2018). Changes in routines causes inconsistency which has significant and often negative effects on a child's development and behaviours (Carrasco, Holgado-Tello, \& Rodriguez Serrano, 2015; Dwairy, 2008). Relevant to my experience, the change in my mom works schedule caused my sister and I to think of a negative reason, rather than a positive explanation. We also chose not to approach or ask any questions, making the experience more stressful. For example, children often show signs of depressive behaviours when trying to cope with fluctuating and inconsistent parenting styles (Carrasco, Holgado-Tello, \& Rodriguez Serrano, 2015). My parents kept their parenting styles the same but changed their routines in hopes we did not notice. However, I believe children notice the little things first.

\section{April 23, 2010}

It was a Thursday night. My mom was at home because she had taken another day off work. I was getting ready for bed, walking to and from my 
bedroom to the bathroom, back and forth. I had my television on, and I could hear it faintly in the background. I remember that I was dreading going to school the next day. I was delaying going to sleep.

I eventually went into my room. I heard my mom walk into the bathroom, close the door behind her, and then walk right back out quickly and return to her spot on the couch. She turned the television louder, but I could still hear her voice from my room. I noticed her tone become tense. I turned my television down and creeped into the hallway.

I would always eavesdrop, listening in to conversations that did not involve me. I was trying to figure out who she was talking to on the phone. At the time, my mom's best friend, my grandmother, and my aunt were all battling cancer. My dad's aunt and uncle had recently passed away from cancer. There were constant conversations about cancer, so I assumed she was talking about someone else's illness.

With the constant stressors impacting their decision to inform their child, parents feel they are not ready to have that conversation. Both parents are unable to explain the illness to their children, so it is easier to avoid. Christ (2000), Fearnley (2012), and Finch and Gibson (2009) examined family experiences with a terminal diagnosis of cancer. They all found that both parents felt that by not informing their children of the terminal diagnosis, they were protecting their children from emotional pain and this perception justified their decision to keep the illness a secret and not inform their children (Christ, 2000, Fearnley, 2012, 
Finch \& Gibson, 2009). My parents kept all decisions to themselves, from financial to health related, they were extremely private. I think it was related to keeping their business between the two of them, in regard to their children, I know they were trying to do what they thought was best for us. By keeping the children uninformed and uninvolved, parents may feel that they are helping to keep their children's lives free from disruption thus allowing them to continue their daily lives without any stressors. Parents end up spending more time and energy keeping the diagnosis a secret (Christ, 2000).

\section{April 23, 2010 (Continued)}

I stood in the hallway for what felt like hours trying to hear the context of the conversation. All of a sudden, I heard her say clearly, "I HAVE CANCER". I stood there completely stunned. Over and over, I repeated that word in my head.

Cancer.

CANcer.

CANCER.

\section{CANCER.}


Her cough, the days off, the continuous trips to the bathroom, it all made terrible sense. I ran into my room. I screamed into my pillow, trying to quiet my tears. My whole world changed in that instant. Why am I not supposed to know? What am I supposed to do now? Is she going to die? Is she not going to be at my graduation? Is she not going to see me get married?

Receiving the news of a terminal illness can cause one to panic, question their past and present, and to fear their future. As indicated above, research examines the impact stress can have on an ill parent's ability to make a decision to involve their children (Fearnley, 2012; Finch and Gibson, 2009, and Rosenheim and Reicher, 1985). As their lives are flashing before their eyes, the parent is typically not mentally capable of fully thinking through how to inform their child of this life changing event (Fearnley, 2012). Knowing their children will be devastated with the outcome, parents may simply keep quiet and internalize their pain (Fearnley, 2012; Finch \& Gibson, 2009). Both parents are living in constant panic what their child's reaction will be when informed of their terminal illness (Fearnley, 2012; Finch \& Gibson, 2009). Ultimately, why parents choose not to inform their children is related to not wanting to cause undue pain and suffering for their child (Fearnley, 2012; Rosenheim and Reicher, 1985; Finch \& Gibson, 2009). Communication with children during these challenging times is an important factor guiding and supporting their bereavement (Fearnley, 2010). However, many parents 
felt at this time it is better to keep illness-related conversations to a minimum (MacPherson 2005, 2008; Christ, 2000). While the healthy parent may have mixed opinions about informing their child of the illness and the child's involvement throughout the process, they may choose to avoid causing stress to the ill parent (Macpherson, 2018). As described above, my mom decided it was best for my sister and I not to find out about her diagnosis. This was done not to be deceitful, but to protect us from any pain and emotional distress related to the situation. My parents know me best, and knew I would have changed my routines, school participation, and extra-curricular activities in predicting the worst. In order to keep our lives, the same, my parents kept the illness a secret until they found out more information and future steps involved in fighting the illness. Families are striving for homeostasis and normality while preparing for the unimaginable changes to everyday life that will come. More often, healthy parents do not have experience caring for a terminally ill spouse and are learning their trial and error (Beale, Sivesind \& Bruera, 2004).

Once the child knows of the illness, the parent is no longer in control and able to protect their child from the pain of that knowledge. However, Christ and Christ (2006) found when parents think they are keeping their diagnosis a secret, their children are often already aware of the illness. Children revealed that they often listen to conversations through cracks of doors and on phone lines, eavesdropping in order to 
gather information kept from them (Christ \& Christ, 2006). As a child, I was always one to listen to conversations that more often than not did not involve me. Knowing this, my parents should have been a little more cautious, however, my mom was not in her right frame of mind. I believe many parents are in similar situations when being involved in a cancer diagnosis, they are probably in a haze state, experiencing the unimaginable. A child will typically feel betrayed by their parent when learning this information indirectly. This disconnect may discourage a child from approaching a parent to ask questions about the illness and the child may feel left out and alone. Similar to my experience, I used the internet to find out most information and avoid my parents in fear of sharing my secret of knowing. Involving children in conversations around illness and keeping them informed can allow children to feel a sense of control and belonging within the family unit (Christ, 2000).

Health care professionals such as nurses and doctors may not be able to provide much support or time to advise families on whether or not and how to involve their child in illness-related discussions Many medical professionals choose not to engage in these types of discussions as they feel they are not trained to counsel parents on this and feel it is a decision solely for the parents to make (MacPherson, 2018; Winter et al., 2017). There is limited research on the counselling provided to children and families beginning and on a journey with terminal cancer. My experience in the beginning stages of the illness is non-existent as my parents were 
unaware my sister and I heard her phone call. Therefore, we did not seek any support resources as they were not offered. My parents on the other hand never believed the benefits of therapy and counselling and would have denied services. MacPherson (2018) asserted that most practitioners are aware that children want to be informed about parental illness but know that they are not in a position to offer information to children without parental consent. Oncology professionals should be encouraged to create relationships with their patients and their families and be able to assist them in all aspects of the illness, including those that may be causing unnecessary stress, to support their overall well-being (Fearnley, 2012). MacPherson (2005), Harris (2003), and Fearnley (2012) support the idea of medical professionals being encouraged to guide the family system as a whole. Although, nurses and doctors might not have the answers, they have the ability to refer families for other supports, including counselling, available in the hospital and health care centres. Members of the hospital environment should be working together as a team to ensure these families are best prepared for the life changing events to come. With or without the child's knowledge of the diagnosis, medical professionals and parents are aware of the changes in routine; providing them someone to speak too can help relieve questions, pressures, worries, fears, and start creating a trusting bond (Fearnley, 2012; Winter et al., 2017). Providing children, a chance to speak to a social worker and create a relationship during the 
early stages of the diagnosis can better their ability to cope after their parent loses their battle (Fearnley, 2012).

\section{April 23, 2010 (Continued)}

All of a sudden, I felt the overwhelming need to escape. I got up from my bed and packed a bag. I grabbed anything I could to hide the fact that I was crying. The fact that I knew. So many thoughts were running through my mind. My sister was not home. My phone was about to die. I did not know where I was going, and I did not care. I needed to escape.

I ran through the kitchen and through the front door, yelling behind me that my friend is outside, and l'll be back in a bit. I ran down the street. I have always been terrified of the dark, but my adrenaline was rushing through my body, so I just kept going. I got far enough from my house that my parents could not see me from outside of the house and I sat on the side of the road. Bawling my eyes out, full of confusion and unanswered questions, I called my boyfriend. Putting my adult voice on, casually asking, "What's up?" I end the conversation quickly. He's busy and I panic so I call my sister. I was unsure if I should tell her or not. As soon as she answered, without thinking, I screamed out, "Cancer. Mom has cancer." Frantic, she asked me where I was and tells me she's on her way.

I get in the car. I tried to calm myself down as best I could. My mind was thinking the worst. Unsure of the steps or diagnosis process of cancer, I automatically think lifelong illness that leads to death. Will it happen today or 
tomorrow? I wondered why my mom has not messaged me king where I am. It's 11:30 p.m. on a school night. I cannot even imagine going to school the next day, but I have no choice.

\section{June 14, 2010}

Minutes, hours, days, months go by. No news and no one mentioned anything to me. I was unsure if I should ask questions or if that will make it worse. I constantly wondered what was happening to my mom. I regretted every moment I chose not to spend time with her, every fight I caused. I could not help but think, what if this is my fault? Every night I would want to tell her I loved her, tell her how important she is to me, and how I would not be able to survive without her. Then I would second guess myself in fear that she would suspect I knew because I did not do that before. I wanted to help as much as I could. Nonetheless, my mom was determined to ensure no one would notice a change, and nothing would take her independence.

Google became both my therapy and my worst nightmare. Without answers, the more questions came. With more questions, my fear intensified. Many nights were flooded, and many mornings were blinded. My world was dark.

Children often take it into their own hands to find information, however, there are consequences when there are no supports in place to allow them to discuss the information and ask questions (Beale, Sivesind, 
\& Bruera, 2004; Fearnley, 2012). Providing clear and age appropriate information can help decrease the chances of the child having frightening fantasies and nightmares about the present and future (Christ \& Christ, 2006; Turner et al., 2007). The terminally ill parent may not be able to comfortably have an open conversation with their child. At this point, there may be several indicators of the severity of the parent's illness to the child, for example, hair loss, weight loss, doctors' appointments, intravenous line, etc. Many parents in this situation believe it is best for them to shelter their child and not change their image of the ill-parent from one of carers to one needing care. In my experience, my mom's illness was blind... in the beginning stages. She had the slightest cough someone might associate with the flu or clearing their throat, but overall looked healthy. Having this experience and finding the cancer at an early stage may have impacted their decision to included my sister and I. Christ (2000) and MacPherson $(2005,2018)$ identified that the ill-parent will make decisions based on their own needs, often reflective of their ability (or inability) to process their diagnosis. This can lead to a lack of readiness to inform their child. The healthy parent does not want to pressure the illparent or cause additional stress therefore, the healthy parent will usually agree with what the ill-parent has decided is best for them and their children.

Biank and Werner-Lin (2011) assert that children do not have the emotional and cognitive capacity to understand the processes associated 
with a terminal diagnosis. It has been argued that children are not able to understand the information given and therefore it is unnecessary to include them in discussions around illness (Biank \& Werner-Lin, 2011; MacPherson, 2005). However, young children are in fact able to understand the general idea of death and of loss, but in making sense of these circumstances they are in need of constant love and affection to ensure they know they are supported and are not alone (Johnson, 1999). Children, and I would assert adults as well, also require time to process information and ask questions to understand what changes are taking place (Johnson, 1999). Futhermore, being left out forced me to use the internet, which is unable to determine individual diagnosis and stages, Therefore, even when my Mom was able to seek treatment, I was looking up statistics on the death rate of lung cancer diagnosis's. To help children better understand the concept of death, it is important to use resources such as appropriate books and movies which can make the topic more approachable.

On the other hand, Christ (2006) and Fearnley (2012) argue that an child can handle grief and that participating in the diagnosis helps with their emotional development and their ability to process the information given. Having children involved during the illness leading to death can help them understand the illness, however, it is important that they are not left with complete caregiving responsibilities (Christ, 2006; Fearnley, 2012). Christ and Christ (2006) state that children have the cognitive 
ability to understand when something is wrong and may try to paint a picture to fill in the gaps of information. I often tried to find information regarding my mom's illness without knowing any specific details. This led to overthinking my future, family, and the fact that I might lose my Mom. Without hearing the conversation, seeing my mom take time off work would have caused my sister and I to try and piece together reasons for the change. Children may also feel left out or neglected at this stage as their parents are forced on doctor appointments and finding information, they lose energy and focus of child-driven activities (Christ \& Christ, 2006). 


\section{Bargaining: Treatment}

\section{The "if onlys" cause us to find fault in ourselves and what we "think" we could have done differently.}

(Kübler-Ross \& Kessler, 2005)

Bargaining is the feelings of wanting to negotiate the death of a loved one or devoting your life to helping orders in hopes to wake up from a bad dream (Kübler-Ross \& Kessler, 2005). Kübler-Ross and Kessler (2005) explains this stage as the feelings of negotiating with pain, trying to bargain "our way out of the pain" (p. 17). These feelings allow the individual to distract themselves from their pain, keeping suffering at a distance and are constant. Bargaining can be seen as hoping to die instead of your loved one before death, turning into hopes that your loved one's death will be painless, and bargaining to reconnect again in heaven if death is inevitable.

\section{July 13, 2010}

My mom's cancer needed to be treated and the symptoms of cancer could now not be ignored. My parents chose to bluntly inform my sister and me of my mom's illness through a sentence, rather than a conversation. This happened a day or so before her treatment began. My dad took on an authoritarian parenting approach, resulting in often one-way communication with little negotiation to rules or routines. Therefore, we often refrained from asking questions or voicing our concerns. The first treatment option was surgery. 
My mom underwent surgery to have the right part of her lung and two lymph nodes where the cancer was found removed. Her total hospitalization period was four or five days, followed by treatment at home.

At the time, I wrote a note to my mom:

I'm proud of you, mom. You always seem to amaze me with the strength you have. If it's from how you deal with me, my sister and dad, to overcoming such a serious surgery. I hope everything is going well. I'm sorry I'm not coming today, but I will hopefully be there tomorrow.

My mom and dad woke up early to go to the hospital. I was at home and I refused to go to school. Fearing the future, I remember laying in my room, not wanting to think or breathe. I just wished I was going through this ordeal and not my mom. My parents did not think it was a good idea for my sister and I to be there at the hospital that first day. They would decide what day and time was best for us to go and see her. My parents believed it was in our best interest not to be involved. Whether or not that was the best approach, it was what they felt was needed during this challenging, confusing, and upsetting time.

A terminally ill parent will undoubtedly be afraid of the battle they are unprepared to face. However, it is important for them to realize the support around them. Family can encourage them to keep going when they are feeling low and reassure them, they are not alone in the fight. My 
mom's treatment plan started with surgery. Doctors would provide suggestion to my parents on possible treatment plans, however, the one deemed most successful to battle the cancer was the one chosen. From my experience, these treatment plans normally incorporated several different methods of treatment, following a remission period to see the success. Partial remission is defined as the period of time after treatment checking if the cancer will begin to grow again (National Cancer Institute, 2019). On the other hand, complete remission is all signs and symptoms of cancer have disappeared (National Cancer Institute, 2019). After five plus years of being in remission a patient is considered cured if no signs or symptoms are present (National Cancer Institute, 2019). A strong family connection and presence throughout treatment can inform the path the terminally ill parent may choose. I believe doctors hold the knowledge in what treatment plan is best for their patients and provide options to patients to allow them to feel in control of their disease. By allowing the family to be involved in the treatment can help them cope with the side effects associated. Harris (2003) and Finch and Gibson (2009) note that when children are involved in the treatment process, those social interactions and family bonding can provide the ill parent with a greater quality of life for themselves and their children. Involving children in a way that is best suitable for the entire family was most beneficial. This often involves slowly preparing children for what is expected to come by introducing the illness in small doses and allowing time for the children to ask questions 
and process the information given. My parents did not provide me with time to digest the diagnosis as my mom's surgery followed quickly. I remember sitting at home as my parents left for the hospital wishing I was there to help. My parents also lacked the ability to educate me on the process and logistics of the surgery, making the waiting time to see her more agonizing.

Biank \& Werner-Lin (2011) conducted research on parental awareness of the actions involved for a do not resuscitate (DNR) and allowing the child to ask questions of practitioners to better understand the process. Providing children with a perspective from people outside the family can help reduce self-blame and invite further questioning. By allowing children to actively learn about and make sense of the illness with others, parents can open up communication with their child and encourage them to share their challenges and discomforts around the illness. Bronfenbrenner's second level, mesosystem, involves the relationships between individuals in the microsystem (Neal \& Neal, 2013). Parents should be speaking with teachers, other professionals, and family involved in their child's life to check in on any behaviour changes associated with the diagnosis. Having these conversations can help parents speak to their children at home possibly making it easier for the child to adjust. The family as a whole can then encourage open dialogue to help children and other family members to better understand the illness and 
what each other is experiencing. These discussions can help to reduce any guilt the child is feeling and let them know that they are not at fault.

Many parents believe that their children's memories of their ill parent will be of their last experiences together (Christ \& Christ, 2006; Porterfield, Saldinger \& Cain, 2004). Therefore, the ill parent may choose to keep their children at a distance from them while they are in the hospital or hospice. They may choose to not see their children in their final days in hopes that their children will remember them in health and in happy times. Christ \& Christ (2006) indicate that children's past memories can cause them anxiety and frustration when visiting their parent in the hospice setting. Parents can open up discussions with their children concerning their parent's illness and the changes they may see. Parents can also judge the scene and excuse their children when medical staff are completing dressing changes or washroom routines that may cause uneasy feelings. In my experience, when my Dad took me to the hospital to visit my Mom, he explained some of the visual hospital machines she was connected too to help limit my anxiety. By actively involving children in their parent's hospital stay and allowing them to express their thoughts, feelings, and questions can help them to feel less anxious. Children are often stronger and more resilient than adults believe them to be. Parents often feel a sense of relief of some stress when their children are involved and they can help their children to understand the illness (Harris, 2003). Christ \& Christ (2006) discuss the importance of hospital visits for children and the 
excitement that children can feel when they are able to visit their parent. By participating in everyday activities and normalizing the hospital environment, for example, walking around the hospital, helping the healthy parent locate the ill parent's room, bringing the ill parent food, and drawing a picture to hang in the hospital room will make the visit a more positive experience and the hospital environment more comfortable for everyone. Tucker, Sugerman, and Zelov (2013) note that children who are not informed or involved in their parent's care often feel abandoned and secluded which can compound to create stronger feelings of isolation. As described above, before my parents let me go to the hospital I felt left out and would often try to fill the gaps of information by using the internet as a resource. When they decided to involve me and allowed me to go to the hospital, I would call my mom and ask her what she needed me to bring and I would pick her up her favorite magazines. This made my visit more fulfilling as I hoped to make her day better by bringing her the things she enjoyed. When children know that they are welcome and helping, they may wish to learn more about the illness and increase their understanding of what is happening (Christ, 2000). With an open conversation, the stigma and fear of the illness can be reduced.

\section{July 19, 2010}

After the surgery, my mom's remission period began. Shortly after, the decision was made for her to go through chemotherapy and radiation. My sister and I were never updated on the progress of her treatments as appointments 
came and went. My parents believed we were incapable of understanding what was happening. For most of the year that my mom's cancer was being treated, I was left with unanswered questions. I would eavesdrop on conversations, but I was rarely was able to find answers to my questions. After a year went by, my family was told the CANCER was gone. Everything was perfect and everything was going to be okay after all. I was happy. I thought my life was back to

normal. 
The United Nations Convention on the Rights of the Child (UNCRC) consists of 54 articles that address the rights of child and when followed by governments and citizens, help each child reach their full potential (Committee on the Rights of the Child, 2005). The UNCRC acknowledges a child's basic human rights, however this section will focus on acting in the best interest of the child (Committee on the Rights of the Child, 2005). Children are experts of their own lives and should have the right to make decisions for themselves. I believe if my parents involved me in a discussion regarding my mom's illness, it would have allowed us to have a discussion about what may help with my ability to understand, become aware, and face the illness myself. Although the UNCRC provides individuals and organizations with expectations for children's rights, more often than not children themselves are not informed about their rights. Related, adults often believe that children are too young to make decisions for themselves. According to the Canadian Coalition for the Rights of Children (2012), approximately $75 \%$ of young individuals are unaware of how to practise their rights or respect the rights of others. Many Canadian citizens claim to respect the rights of the child, but more than half are unaware of children's rights and the UNCRC. The Committee of the Rights of the Child (2005) describes early childhood as the most critical period of children's development and realization. Young children are developing their social, emotional, physical, cultural, and personal identities and these inherently influence their future adult selves. Children should be taught about their rights at a young age so that they develop an 
understanding of their abilities and impacts they can have throughout their lives. Without my own knowledge of the UNCRC, I was unaware of how involved a child can be in matters involving them. Children's voices should be heard.

The UNCRC gives children the right to have their best interest taken into account as the first and primary action or decision that concerns themselves (Committee on the Rights of the Child, 2005). The parent is provided the right to judge a child's best interest but can not "override the obligation to respect the child's rights under the convention" (Committee on the Rights of the Child, 2005, pg. 3). Meaning, all decisions and discussions are made with the fundamental goal of promoting and reassuring the child's happiness, security, mental health and emotional development are the basis of the decision. (Committee on the Rights of the Child, 2005). Therefore, if the child is too young to legally make a decision or deemed too young to be involved, then the 'best interest of the child' will be used to make a final decision. However, no matter the age of the child, matters can be explained in child-friendly terms to allow their point of view to come across and assist in making the right decision based on the child. No matter what decision a child makes, the end result can be based on the 'best interest of the child', but at least their voice is heard, and their feelings are involved in the decision making.

\section{April 22, 2011}

Eight months later and it was Christmas time. We were joined by our extended family. After dinner, everyone pitched in to clean up after the meal. 
With the busy-ness buzzing all around, I listened in on different conversations. I heard my mom says her cancer was back.

Stress immediately overcame my body.

I walked away to try to get away from what I had heard, but my cousins

followed me. Despite needing space, I would not be left alone that night. I sat in the crowded and loud room filled with laughter, straight-faced and emotionless.

My mind was elsewhere.

My worst fear came true. 


\section{January 14, 2013}

Three years after her first diagnosis, I was told that mom's cancer was back. Surgery was not an option this time. Chemotherapy and radiation were the only treatments available now. Her chemotherapy went on for a long time and she suffered extreme side effects that altered her daily activity.

Although I was still not 'allowed' to be involved in any doctor's appointments or decisions, now that the side effects were painfully obvious my sister and I knew that she was fighting a terrible disease. Once in a while, I would visit my mom at work and notice how weak she was getting from her treatment. It broke my heart. I thought of death and all the milestones she would not be around for. I could not imagine life without my mom.

If my dad was busy, my sister or I would take my mom to her chemotherapy appointments. I think we were only allowed to go with her because no one else was available to take her. We were still kept in the dark about any details of her diagnosis, treatment, and prognosis. It was surreal being in the large room at the clinic, watching people sitting in chairs with IVs undergoing chemotherapy. The orderly would come around with blankets, cookies, and juice to give to the patients because they would get cold and weak from the treatment. I was learning about the illness and treatment through my observations at the chemotherapy sessions. Some people had family and friends with them to keep them company. Others sat by themselves. I thought about what toll this must be taking on my mom. I was happy she was not alone. 
Children have an attachment to their parents and rely on them for security. Experiencing a parent suffering from a terminal illness is unsettling and is characterized as a permanent physical separation from their attachment figure (Howell, Barrett-Becker, Burnside, WamserNanney, Layne, \& Kaplow, 2016). The inclusion of a child in their parent's terminal illness can allow them to feel closer to their ill parent. Presence and information can help the child to understand the disease, what its cause is, and what future treatments need to take place. This can supportively bring the child into the difficult experiences and conversations that the family will have. My parents eventually made the decision to involve my sister and me in my mom's illness and treatment. Being at the hospital around the nurses gave me the opportunity to ask questions and expand my knowledge about the disease. It also allowed me to feel as though I am helping and involved in the fight, showing my mom she isn't alone. Porterfield, Saldinger, and Cain (2004) and Finch and Gibson (2009) explored the involvement of a child in a parent's cancer journey and found that inclusion can help the child to understand that they are not at fault. Children, as do adults, have many mixed feelings associated with such a life changing event (Finch \& Gibson, 2009). It is clear they need time to process and understand what they are going through (Finch \& Gibson, 2009). As with adults, it is important for children to remain engaged in social groups and extracurricular activities to ensure they stay connected to their friends for support (Christ, 2000). 
Teachers are a good resource for families to stay connected to, to ensure there is support offered at school for the children (Christ, 2000).

\section{March 21, 2013}

My mom was the strongest person I knew. She continued to work throughout her cancer treatment. She took care of her family and her mother who was also undergoing treatment for cancer. As best they could, my parents carried on with the same lives as we had before, and we kept the diagnosis a secret from almost everyone. I was constantly reminded not to tell anyone about anything happening at home. I was often confused when family members spoke to me about my mom and they knew more information about her illness than I did. Instead of confronting my parents about it, I acted as though I was ignorant and ended the conversation.

One side effect of mom's radiation that she struggled with was hair loss. As a woman who was always well-dressed with a full face of makeup, dyed hair, and high heels, even to our soccer games, the loss of her hair meant the loss of her identity. It began with several strands of hair on the floor and on the back of her shirt and progressed to clumps coming out when she would run her hands through her hair. Eventually, she shaved her head and got a wig. For about a year, my mom did not take her wig off in front of anyone, not even in front of me. It was very difficult for me to see her feeling so uncomfortable; it made me feel helpless and lost. I did not know how to act around her, what to say and 
what not to say. For a while I struggled to even tell my mom I loved her. I think it was because I did not want it to be even more emotional for me or for her. I did not want to upset her more than she already was. We never said those words often and saying them then would make it feel like a goodbye. Inevitably however, I felt like I died a bit inside every night knowing that I did not say "I love you".

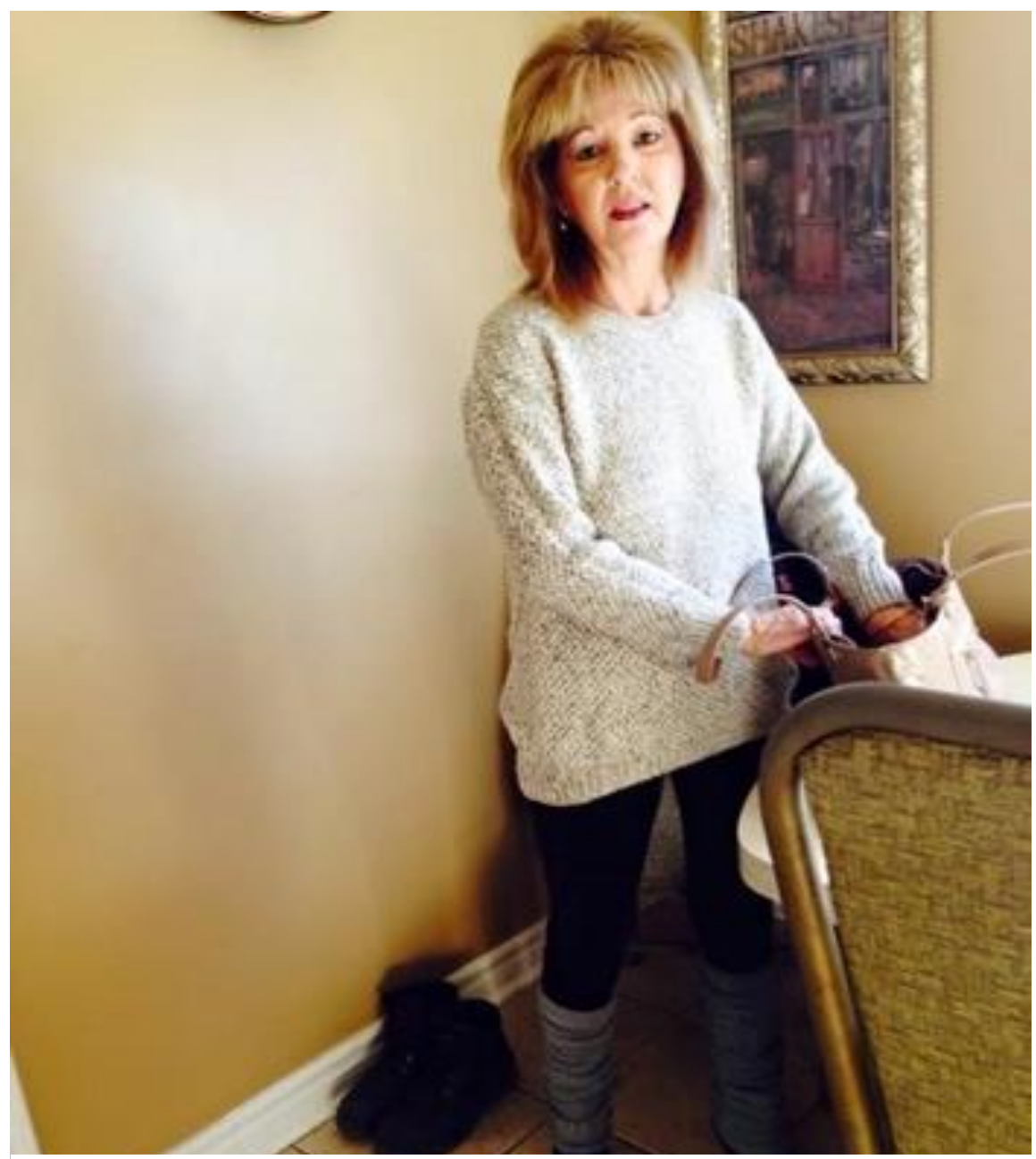

Figure 2: My mom feeling comfortable and gaining her selfconfidence back with her wig on. 
After a cancer diagnosis, families need to make decisions about treatment and future steps. Depending on the severity of the cancer, doctors will decide which treatment option will be most beneficial to the patient, often pairing two or three to be most effective. One treatment is chemotherapy in which is a drug used to delay or slow cancer growth throughout the entire body (American Society of Clinical Oncology, 2019). Another treatment option is radiation which uses high energy rays to destroy a specific location of cancer cells (American Society of Clinical Oncology, 2019). Both result in significant side effects such as fatigue, nausea, vomiting, hair-loss, and appearance change (American Society of Clinical Oncology, 2019). One common side-effect in those undergoing cancer treatments is the loss of hair and this has been identified as one of the most traumatic changes experienced in cancer treatment (Trusson \& Pilnick, 2017). Hair itself is a significant part of many individuals' identity, femininity, body image and esteem (Trusson \& Pilnick, 2017). Not only is there a limited number of women with very short hair or baldness, it is a key physical indicator of cancer (Trusson \& Pilnick, 2017). As shown above, my mom purchased a wig. However, this time in her treatment was the most traumatic for her and for over a year she refused to be seen without her wig. In order to help her experience a change, I cut approximately seven inches off my hair 
length, making it reach just below my ears. I believe hair is something women often do not think of being placed in a situation where you would live without it. Freedman argues, hair loss should stop being treated as an illness and should be seen as society's intolerance of people who look different (Trusson \& Pilnick, 2017). Nonetheless, health care professionals are trained to offer advice, often resulting in women purchasing a wig to disguise their hair loss (Trusson \& Pilnick, 2017). Trusson and Pilnick (2017) did a study on women experiencing treatment related hair-loss, one woman reported taking photos and not recognizing who was in the picture. To date, the pictures I have of my mom without her "normal" hairstyle remain unposted and private. Women often purchases wigs that are similar to their old hair styles in order to feel closer to themselves before and after treatment (Trusson \& Pilnick, 2017).

\section{April 29, 2013}

My life became a constant battle with the unknown. I went to a family member's cottage, thinking it would be a relaxing time. To escape, I thought that experiencing nature would allow me to finally calm my nerves. While sitting by the fire late at night, my aunt brought up my mom and said that the cancer had spread to her brain. Once again, that terrible, overwhelming feeling took over my body and my face went blank. I could not breathe. I ran inside and 
called my sister. I could barely speak because I was hysterically crying. Again, I was left with unanswered questions and that now all too familiar panic state. At this point, my mom quit her job. My dad had to go back to work after he had been off for years due to an injury he incurred at work. My mom was getting weaker. Now that my dad was not home as often, I was more involved in caring for her. I knew all my mom's medication schedule. I cooked her all the food she was willing to eat. I tried everything to make her eat. Eventually she lost her independence. Despite my new role as her caregiver, I will still be kept in the dark about her prognosis.

A child of a parent diagnosed with a terminal illness will be asked to take on additional responsibilities in their family to assist their ill-parent (Christ, Siegel \& Sperber, 1994; Jantzer et al., 2013). Melcher, Sandell, and Henriksson (2015) explored children's experiences of adapting to responsibility due to a parent diagnosed with a terminal illness and found that children were greatly affected as they took on new roles and responsibilities. Children often neglected social outings with their friends, coordinated healthcare interventions, comforted parents, and protected parents from other persons that might be draining (Melcher, Sandell, \& Henriksson, 2015). Research suggests that children may withdraw from social interactions and outings in order to help with adult responsibilities and care giving, one child reports their friends eventually stopped calling 
(McPhail, Dwyer, Hanemaaver, \& Preyde, 2017; Melcher, Sandell, \& Henriksson, 2015). Unfortunately, and, more often than not, these children's friends are unable to understand their experiences, emotions, and challenges (McPhail, Dwyer, Hanemaaver, \& Preyde, 2017). Many children experienced changes in family roles, resulting in children taking on more household responsibilities and increased financial strain (Leedham \& Meyerowitz, 1999; McPhail, Dwyer, Hanemaaver, \& Preyde, 2017). Referring to my previous point, I chose to spend any free time with my mom and would research recipes to get her to take in more fruits and vegetables in hopes to make her feel better. I remember even on my birthday choosing to stay inside and spend it watching television with my mom, nothing seemed as important. Nonetheless, most children are grateful for the change in dynamic as they are able to build a concrete relationship with the ill parent, have a greater love for family, and learn how to prioritize their needs and wants (McPhail, Dwyer, Hanemaaver, \& Preyde, 2017).

\section{June 24, 2015}

Eventually, we had a hospital bed brought into the house. Mom needed a lot more support from us, and we were there to provide it to her. We had to carry her into a wheelchair and wheel her to the bathroom. My sister and I took over the housework. We had nurses regularly visit my mom at the house. Then I 
was told she was palliative. As it was not a word, I was familiar with, I asked what it meant. "Comfort care." Again, my future flashed through my eyes. How am I supposed to live without my mom?

Clinicians have the challenging role to communicate with families the prognosis of their treatment and cancer. Eventually, there comes a time where treatment is exhausted and no longer effective, and doctors, nurses, and medical staff must speak to the family about the next steps. Effective communication from medical professionals, patients, and families is important to ensure pain management, psychological health, and quality of life. The National Council for Palliative Care defines palliative care as "active holistic care of patients with advanced progressive ill-ness" (Canzona et al., 2018, p. 4159). The purpose of palliative care is to provide relief care for the patient which can be done while receiving treatment. Oncology professionals speak to families during transitions and can be challenged to communicate fully the severity of the situation and the future outcomes (Canzona, Love, Barrett, Henley, Bridges, Koontz, \& Daya, 2018). Nurses are often faced with situations that patients and their families do not understand what is happening and why, for example, my confusion about comfort care. However, their care and time is invaluable; with respect to comfort care, the National Council for Palliative Care quoted one patient as saying, "I am glad we're doing this comfort thing" (Canzona et al., 2018, p. 4161). Oncology professionals describe comfort 
care as one of the final stages of palliative care. It seeks to keep the patient comfortable and out of pain, but no treatment plan is in place, resulting in the final stages before end of life (Canzona et al., 2018). My mom chose to spend the finals days in the comfort of our home, my living room was transformed into a hospital room, and we were my mom's twenty-four hour, seven days a week, carers. My mom eventually lost her independence, and simple tasks, like brushing her teeth seemed impossible. Eventually, she was bed ridden. I believe medical professionals could have explained the circumstances better in order for us to understand the rapid decline we were about to face.

\section{December 4, 2015}

I did not want to do anything but stay home with my mom. I thought back to all the times I upset my mom and regretted every fight I caused as a child that may have hurt her. It was the holiday season again and we celebrated Christmas. More family members were coming by. At this point my mom had no energy to hide her disease. She lost an extreme amount of weight and had no interest in eating. It was only a matter of time now.

\section{February 5, 2016}

That time came on a Friday night. My dad had been in a car accident, so he was home for several weeks to recover. I came home from work that evening and sat on the couch beside my mom in her bed. I took her to the 
bathroom, and she started leaning to her left side with her eyes rolling back. I screamed for my dad. We rushed her back to her bed, and I called 911. My dad told me to pack her a bag. I ran all over the house, panicking and wanting to cry, but at the same time I wanted to be strong. This was the first time I had seen an ambulance up close. The paramedics came inside the house and I can still hear her saying, "Ouch, you're hurting me," as they moved her from her bed to the stretcher.

That entire night then became a

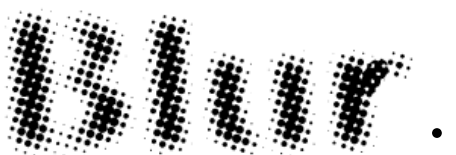




\section{February 5, 2016 (Continued)}

After some time, we were in the emergency room. My father, my sister, her boyfriend, and I surrounded my mom in the hospital bed. She was convulsing. Her head was twisting, and her upper body was contorting unnaturally. There was nothing we could do. She could hear us, so we told her we loved her. It was 4 a.m. on Saturday when my dad suggested we go home to get some sleep. He said he would message us in the morning when it was time to come back. After a short rest, we returned and spent all day Saturday at the hospital but were unsure of what was happening. Every time the doctors or nurses came to speak with us, my dad walked with them out of the room and talked in the hall.

\section{February 7, 2016}

My dad stayed overnight with her again and we came back Sunday morning. It was Super Bowl Sunday and we had a lot of visitors in the room. My mom was unconscious and wearing a breathing mask. Everyone tried to keep the mood light and the conversation flowing, but I could not take my eyes off my mom. I just wanted to hear her voice again.

We watched up to the half time show of the Super Bowl. I fought to stay longer, but the family consensus was for us to go home and rest. A family member stayed with my mom so my dad could go home, shower, and relax a 
bit. We dropped my dad off at a local bar for him to have a beer and then had to drive back to the bar to pick my dad up.

We drove back to the hospital.

My dad told us to pull up into day surgery pickup/drop off.

He told me to get out of the car. He said,

\section{"We lost her."}


With most ill parents attending doctor appointments frequently to ensure their palliative experience is comfortable, they often believe their practitioners and doctors hold all of the knowledge about their illness. However, as indicated by Arber \& Odelius (2018), medical professionals may not have the information wanted by patients and families and feel unequipped to support them, particularly young family members. For example, when approached by parents for advice on handling difficult conversations about illness with their children, nurses may avoid the question all together (Arber \& Odelius, 2018). In my experience, I wish the nurses were able to tell us when my mom was going to pass, because maybe we would have been able to stay. However, I also believe that we often think nurses are able to know exactly what the patient is feeling and experiencing when their unconscious, when in reality, I do not think anyone is able to know those answers. Some nurses have admitted that they are inadequately trained, or not trained at all, in situations related to talking to children about terminal illness and instead may distance themselves from these matters (Arber \& Odelius, 2018). The needs of the children are not always recognized by health care professionals; their primary focus is on the patient battling cancer. However, once the patient has passed, families are left dealing with the death of a loved one alone. After my mom passed away, no one 
offered my sister and me counselling, no one contacted us; we had so much assistance... then nothing.

Elisabeth Kübler-Ross (2015) identified five stages of grief that individuals experience when going through the loss of a loved one. Every individual experiences' loss in a different way and will experience each stage at various times and may not experience all stages. The stages, while organized sequentially, may not be experienced in that order. They were identified to guide individuals through their loss, helping them cope and live with the loss of a loved one (Kübler-Ross \& Kessler, 2015). The first stage, denial, described above is characterized by overwhelming and seemingly meaningless feelings experienced, often while in a state of shock (Kübler-Ross \& Kessler, 2015). As individuals deny their feelings and the events that took place, it can temporarily help them deal with the pain associated to the loss (Kübler-Ross \& Kessler, 2015). Next, feelings of anger dominate their emotions in the second stage of grief. Following is the third stage, bargaining. Here, the individual may think of scenarios where things unfold differently, wondering, "If only..." Kübler-Ross notes that at this stage, the individual will often wish that they had been ill instead, or that the illness was identified earlier. The fourth stage of grief is depression and is characterized by feelings of being left out and coming to the realization that their loved one is not coming back. (Kübler-Ross \& 
Kessler, 2015). It is described as a necessary step to healing, letting the sadness and emptiness take over helps individuals explore their loss and allow you to grow stronger (Kübler-Ross \& Kessler, 2015). Finally, the fifth stage of grief is accepting and acknowledging that the loss is real and that there is a new reality to adjust to. David Kessler, a co-author, identified a further sixth stage: finding meaning. It is during this stage that the individual comes come to terms with their loss (Kübler-Ross \& Kessler, 2015). Children experiencing the loss of a parent will go through countless feelings throughout their life, and cycle through these stages of grief (Christ, Siegel \& Sperber, 1994; Beale, Sivesind \& Bruera, 2004; Christ, 2000; Fearnley, 2010). Losing a parent will always be hard, but the support of family and friends will help guide them through their pain and loss (Beale, Sivesind \& Bruera, 2004; Christ, 2000; Christ, Siegel \& Sperber, 1994; Fearnley, 2010). 


\section{Depression: Loss of Mom}

When a loss fully settles in your soul, the realization that
your loved one didn't get better this time and is not coming
back is understandably depressing. If grief is a process of
healing, then depression is one of the many necessary steps
along the way.

(Kübler-Ross \& Kessler, 2005)

Depression is defined as an empty yet overweleming feeling of grief making one feel as though they are in a fog of intense sadness (Kübler-Ross \& Kessler, 2005). Depression in this stage is not a mental illness, but an appropriate response to the depressing situation of losing a loved one (Kübler-Ross \& Kessler, 2005). Kübler-Ross and Kessler (2005) describe this stage as "a loss fully settles in your soul, the realization that your loved one didn't get better this time and is not coming back is understandably depressing" (p. 21). One mourning the loss of a loved one will feel as though there is no point in their lives continuing, question if these feelings of sadness will move on, and wonder if this is how life will continue. At this stage individuals need support, but by those able to accept the sadness without telling them not to be sad.

\section{February 7, 2016}

It was my worst nightmare come true. I got back into the car. I was shivering and shaking. I kept hearing, "She's gone," over and over in my head. I wanted more than anything to turn back time. 
As soon as I got back to my house, I ran to my mom's room. I sat on my mom's bed, crying into her pillow and thinking about the last twenty-four hours. I was angry that my boyfriend was not with me. I was mad at my sister who said it would not happen today; it did. I was upset that I left the hospital when I knew deep down that I should have stayed. I regretted the last five years of my life and thought of all of the things that I could have done differently. I wondered if it would have kept her with us longer. I wished I stayed by her side every second of every day. I should have quit my job. Looking back, I would have done so many things differently if I knew my time was as limited as it was.

But that morning came. It felt like it was all a bad dream.

\section{February 8, 2016}

I called the health care equipment company to remove the hospital furniture we had in our house. I set up our meeting with the funeral home to make arrangements for my mom's service. There was a long list of people to call. Overnight, I went from being a teenager to a responsible adult. I had to 
focus on the menial tasks that needed to be done or I would have been consumed by my grief.

Calling family and friends was overwhelming; it was more than I could handle. My father was unwilling, or perhaps he was unable, to answer the endless questions that would inevitably follow when family and friends heard about the death of a fifty-seven-year-old woman who no one knew was even sick. The phone calls were unbearable. Not only did we have to explain how she died, we had to relive the last six years of her cancer journey. Some people were frustrated that they were not told sooner. It was difficult for me to justify my parent's decision to keep the diagnosis and prognosis a secret when I disagreed with their decision to do so.

The staff at the funeral home were kind and gentle; it seemed like they thought we were all going to break into a million pieces if the wrong thing was said. Going over the arrangements was traumatizing, having to plan my mom's funeral. There were many questions asked about my mom's upbringing and life, but I could hardly answer them. Instead I was wondering, Was I a bad daughter? Did I not ask any questions about my mom as a child? Why was I not able to share her story? I thought about how I would never be able to have a conversation with her about this. While the answers were not essential to the funeral service, they did leave me feeling empty. 
Bereavement is losing someone from death and the adjustments that follow (Johnson, Torres, Sykes, Gibson, \& Baker, 2017). On the other hand, grief refers to the feelings associated to the loss including mental, physical, social, or emotional difficulties (Johnson, Torres, Sykes, Gibson, \& Baker, 2017). Many loved ones feel guilty and that they should have had the illness instead. Those grieving the loss typically experience extreme challenges with trying to cope with knowing their loved one is not coming back (Harris, 2003; MacPherson, 2005). Losing my mom was unimaginable but being asked questions about her and not having the answers was brutal, I couldn't even ask her. Everything around me felt blank, emotionless, empty; my house lost the feeling of warmth. With the often-overwhelming feelings associated with new responsibilities, changes of environment, and different routines, families tend to experience emotional distress and disconnect (Buchbinder, Longhofer, \& McCue, 2009). In order to cope with their new reality, the help of medical professionals is essential. Stroebe and Schut (2010) explored grief and support using the Social Readjustment Rating Scale. The death of a spouse and death of an immediate family member were identified as causing the most readjustment. Intervention and grief therapy as support for those experiencing grief and bereavement were found to greatly reduce distress felt when compared to those families not receiving those supports (Stroebe \& Schut, 2010). Oncology professionals should work alongside social workers to provide counselling support and services to families both 
before and after the loss of a loved one to assist with their coping (Fearnley, 2012; Harris, 2003; MacPherson, 2005). Medical professionals were not involved nor were they offered. Losing a parent feels as though you are hitting the bottom, and I lost all feeling, I was numb.

\section{February 8, 2016 (Continued)}

At one point, my family was asked if we wanted an open or closed casket. Initially, I insisted on an open casket or at least the opportunity to view my mother's body before the funeral. I wanted to see her one last time. However, my sister fiercely opposed having my mom's casket ever opened. She was adamant that my mom would want me to remember her as she was when she was healthy and happy with her hair and makeup done. A few months earlier, my grandmother died in my cousin's home, my cousin sent me a photo of my grandmother's face after she died. That image of my grandmother came to me in recurring nightmares ever since. My sister did not want me to close my eyes at night and see my mother's lifeless corpse. We decided on the closed casket.

We proceeded to go through to a viewing area with various caskets and urns on display for us to choose from. My body felt numb. We were then asked if we wanted to watch the cremation. I could not believe this was actually happening. 
The phone was still ringing nonstop. Everyone was coming over to our house to visit. My life was a circus.

\section{February 10, 2016}

Two days later, it was the viewing at the funeral home. It felt like the service went on forever. Walking into the funeral home and seeing flower arrangements cover the wall was incredible. My mom was special, and the flowers showed me I was not the only one who thought so. It was heartwarming seeing everyone who came to give their condolences, but I was also angry. I looked around the room and wondered who still has their mom in their life. My mom would never experience being a grandmother to my children and my children would not have her as their grandmother. 


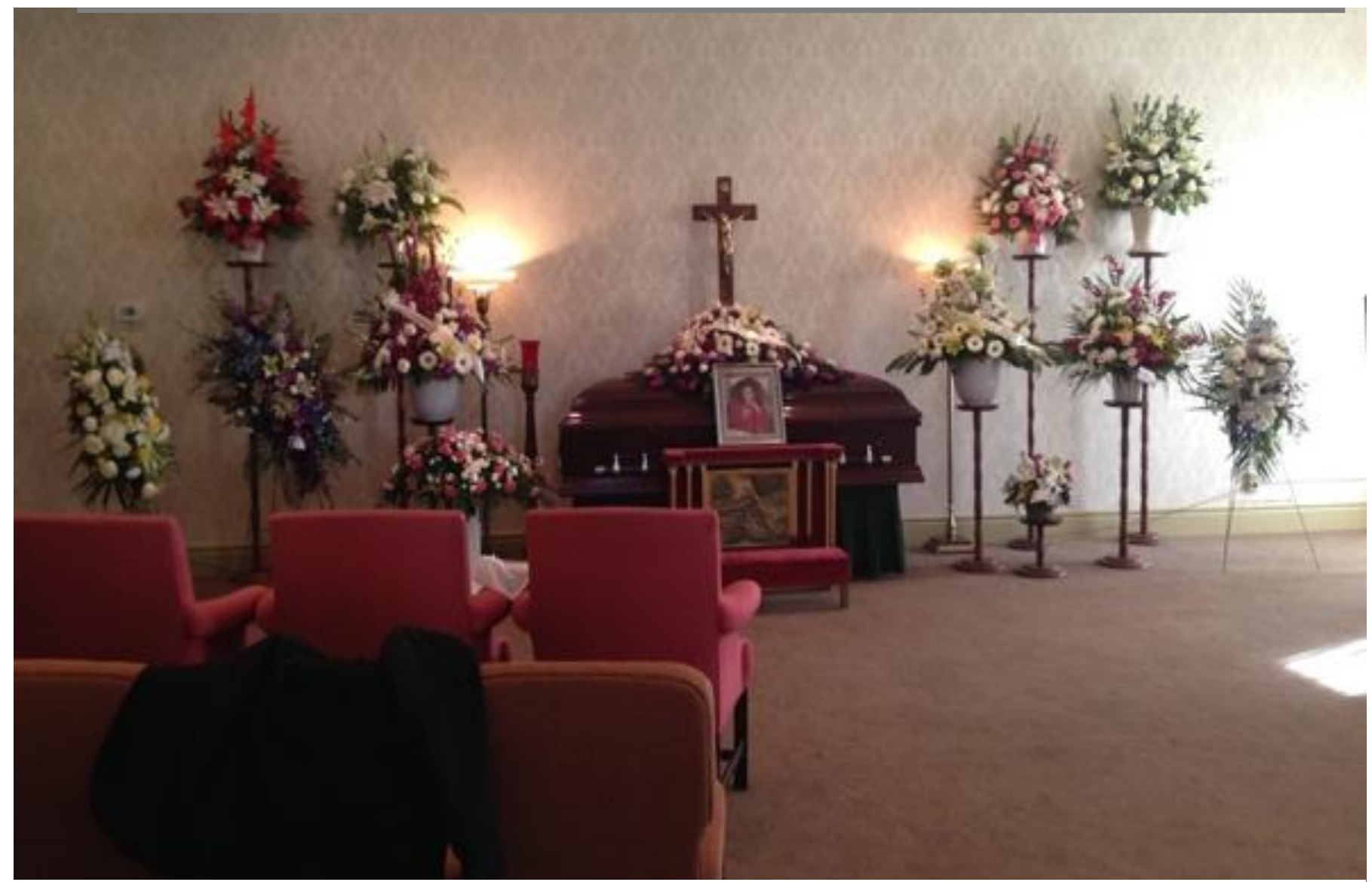

Figure 3: The first time I walked into the viewing room with my mom's casket in the middle of the room. Celine Dion's "Because you loved me" played in the background.

\section{March 1, 2016}

Time went on. I had to get back into my routine of school and work, yet the empty feeling still consumed my mind and soul. The house was different. My mom did everything for everyone and now I was determined to take over that role. I began calling the banks and insurance companies to inform them of her passing and follow the correct procedures to close accounts and complete transfers. I took on the chores around the house and made sure my dad was 
taken care of. I worked 14-hour days and tried to cover our household costs as fully as I could. I did not know how challenging it was to settle an estate when someone passes away. I did not realize the amount of work it takes to maintain a house.

I continued to have regrets that I did not do enough to help and care for my mom. I regretted what I did during the years she was sick. I regretted not spending every minute of every day with her. I wondered whether she knew how much I loved and appreciated her. Now I would never know.

The death of a parent is often unimaginable from a child's perspective. Following the loss of a parent, children can experience overwhelming feelings of guilt and regret as they recall past arguments, fights, and disagreements with that parent (Schilesinger, 2014). A huge struggle I experienced after my mom passed was the regret I felt, as though I didn't do enough, as though I killed her. I remember a few days before my mom went into the emergency room, my sister and I were bathing my mom and she slipped off the stool... shaking uncontrollable... there was nothing I could do... was that what caused her to be hospitalized? Situations that seemed normal, I second guessed, I questioned if I forgot to give her her pills or enough fluids. As the carer, I questioned a lot, making my feeling of regrets intense. A child may regret not spending enough time with the deceased parent, not expressing enough 
love, and not behaving (Schilesinger, 2014). Many children find they are unable to speak of the deceased parent as they deny the reality of their passing and do not want to upset their healthy parent (Schilesinger, 2014). As my family experienced a new norm, there were many firsts we were unsure how to react to; my sister and I did not know if wishing my dad, a happy anniversary would cause him extreme sadness, anger, or happiness. My emotions were scattered. Many researchers have found children that experience rage after the loss of their parent, often feeling angry, jealous, sad, or helpless when they see others spending time with their parents (Harris, 2003; MacPherson, 2005; Schilesinger, 2014). As discussed earlier, the family must adjust their lifestyles and create new routines in order to take on new roles the deceased parent used to complete, and this transition can be very difficult for all family members (Budescu \& Taylor, 2013; Kitsaras, Goodwin, Allan, Kelly \& Pretty, 2018; McLoyd, 1998)

\section{April 3, 2016}

I tried everything that I could to come to terms with the loss of my mom. I even visited a medium; I wanted to connect with my mom. The main message I got from her was, "Everything will be okay." She told me that my mom was not in pain anymore and this gave me some relief. However, I still wanted to do more so I signed up for the Rexall One Walk to Conquer Cancer charity event. Our team was called the 'Cindy-Lou-Hoos' after my mother. I put tireless effort into 
creating fundraising events for our walk including an auction and a garage sale. Overall, I was able to raise $\$ 15,000$ and I also participated in three interviews with different newspapers for the walk. After my team completed the $25 \mathrm{~km}$ walk, I was overjoyed and felt that my mom would have been proud.

As time goes on, it never gets easier. Many people tell me she's in a better place now, but that does not make the grief any easier. Our house is not a home without my mom. The holidays and milestones seem to get harder as every year passes. We have yet to celebrate Christmas. No matter how old you are you always need your mom. 


\section{Acceptance: Dad's Health}

\section{This stage is about accepting the reality that our loved one is physically gone and recognizing that this new reality is the permanent reality.}

(Kübler-Ross \& Kessler, 2015)

Acceptance is not the notion of being okay, but accepting the new reality that our loved one is physically gone (Kübler-Ross \& Kessler, 2005). Kübler-Ross and Kessler (2005) describe this stage as "acknowledging all that has been lost and learning to live with the loss" (p. 26). Eventually, one will use their energy from their emotions and feelings from their loss and use it to invest in their life. One cannot move into acceptance without experiencing grief to its fullest, which will allow us to live our life again. However, one can never replace the love of their loved one.

\section{April 24, 2016}

My dad had an ongoing and constant throat infection. Since his regular doctor's office was far from our house and inconvenient to get to, he was going to various walk-in clinics to get prescriptions to temporarily treat the infection. His ailment started in October of 2015 and continued after my mom's passing away. Eventually he did see his doctor and was then referred to a specialist to take a biopsy from his throat. During this process, he would be anaesthetized so 
he needed someone to drive him to the hospital and without hesitation, I took him to the appointment.

\section{May 5, 2016}

Upon arrival at the hospital, we checked in and waited for his name to be called. It was almost 3:30 p.m. when I saw a sign that said that day surgery hours were from 7 a.m. to 4 p.m. We were both annoyed at the thought of coming back another day for the procedure to be done. Thankfully after a few minutes, a nurse called his name. By this time, we were the only ones left in the waiting area. She explained that they were just looking for a nurse to stay later and that the operating room would be ready in twenty minutes. She said to my dad, "We will take you in now to prepare you for the procedure." I was uncertain about what was happening. I just sat in the waiting room alone and waited.

Often children are put into parental caregiving roles when the other parent is working or has passed away. Children take on the role and complete necessary tasks such as grocery shopping, cooking, cleaning, providing comfort, and assisting with activities of daily living (Gates \& Lackey, 1998). However, without information regarding the diagnosis and being involved in order to understand the situation, children may experience anger and frustration at having to take on these tasks and may feel left out (Gates \& Lackey, 1998). When children are informed and involved in caring for their ill parent, children tend to feel greater 
attachment to their ill parent and less guilt and resentment from going to appointments and completing extra tasks (Gates \& Lackey, 1998). Opposite of my previous situation, I was very involved with my dad's medical appointments, providing me a sense of relief. I found being at the hospital made it less suspenseful then waiting at home.

\section{May 5, 2016 (Continued)}

After two hours, a nurse came to talk with me. She explained that my dad's throat was so swollen that they could not take the breathing tube out without him suffocating; he would have to stay overnight. She advised me to stay close by as he would be moved to the intensive care unit when a room became available. I was completely shocked, confused, and scared. I immediately thought my dad was not going to make it through the night. My sister was at school. I did not know how to handle the situation. I heard my name, I gathered my things, and proceeded to walk to the room to see my dad.

When I turned the corner, my dad was lying in a hospital bed. He was sleeping and seemed to be okay. The nurse said he would be discharged tomorrow. When I went back the next day, we were told that the biopsy results were inconclusive, and we were sent to another hospital downtown for further testing. 
Children describe their feelings as pain, hopelessness, regret, and guilt when detailing their experiences of a parental cancer diagnoses (Tilquist et al., 2016). More often than not, they also associate their home with pain and share feelings of powerlessness, as previously stated, even wishing that they could "die rather than lose a parent" (Tilquist et al., 2016, p. 96). Tilquist et al (2016) shared a girl's experience with her mom's diagnosis of cancer; she described death as “incomprehensible...it's so damn hard when everyone is talking about their moms! I want my mom too!” (p. 96). Many children describe having a "motivation... internal strength that helped them continue living their lives" (Tilquist et al., 2016, p. 96). Children typically have a secure attachment to their parents and often want to take the pain away rather than see their parent suffer. At this point, my dad was emotionally exhausted, having lost his wife two months earlier, I wished it was me.

\section{June 11, 2016}

My dad asked me to take him to his next appointment. We were all worried about what the outcome of the procedure and his eventual diagnosis would be. The night before my dad's appointment, I was sick to my stomach, nauseated and vomiting. However, I was not going to miss this appointment. My boyfriend came with my dad and me, and he drove and parked the car while I helped to register my dad for day surgery. Eventually, my dad was called in and my boyfriend and I went to the waiting area. I laid down on one of the couches 
holding a plastic bag with me, hoping I would not throw up. I felt drained, but I was determined to stay awake and alert in case anything bad happened.

Again, I was left waiting. My boyfriend and I sat in the waiting room for hours. I was panicked and anxious the entire time. I was scared that I was going to lose my dad as I had my mom.

Eventually, the doctor approached us and sat down with us on the couch. He said, "Your dad is doing well. He was in recovery and waiting for the anaesthetic to wear off." Then, the conversation took a turn for the worse. The doctor said the biopsy came back positive and that the mass was cancerous. He said he would meet with his team to discuss further treatment and plan a date for next steps.

My heart sank. I could not speak. The level of fear I felt was unbearable. I just lost my one parent; I could not survive the loss of the other. We had to go home and wait for the next step in the process. The wait was agonizing. I needed the cancer to be gone. Now.

\section{October 8, 2016}

My dad and I met with several doctors and planned a schedule for treatment. My dad had two months before he began 45 days straight of chemotherapy and radiation treatment. The doctors informed us of possible side effects to these treatments and the most common was weight loss. To ensure my dad did not lose too much weight, I made sure my dad ate a lot and had any 
food he wanted to eat. Chicken wings were his top choice. I put my life on hold to take care of him. To this day, I have not missed one appointment with him. I was determined to be there to support and help my dad through this challenging time.

\section{January 29,2017}

After a few rounds of chemotherapy and radiation, the radiologist was surprised at how well my dad was doing. He said my dad was just the fourteenth patient out of his 30 plus years of providing treatment to not require a feeding tube. I was beyond happy and proud of how well my dad handled the process. Today, I am proud to say my dad is cancer free. Of course, we still go for regular check-ups to ensure the cancer has not returned. There are various side effects from the treatment that will never go away. My dad constantly has ringing in his ears. In addition, he has sores in his mouth which makes eating most foods impossible. My dad frequently gets frustrated by these health issues because they have no cure. All in all, my sister and I are grateful we have our dad with us, even if he is grumpy most of the time.

Once a tumor has decreased in size by fifty percent, the individual is considered to be in remission (Hersh, 2019). However, remission is not considered a cure and individuals are to be checked regularly to closely monitor the cancer (Hersh, 2019). 
There is a five-year period to reach before one can be considered cancer free (Hersh, 2019). My dad is heading into his third year of being in remission, however, I am in constant fear of the cancer returning. Without a doubt, experiencing the diagnosis of cancer will change the relationship a child has with their ill-parent. Although, remission does not mean cancer free, it is an important milestone for families to celebrate as they are one step closer to clearance (Hersh, 2019). 


\section{Learn to light a candle in the darkest moments of someone's life. Be the light that helps others see; it is what gives life its deepest significance.}

(Bennett, n.d)

Finding meaning is the final most critical stage of grief added as an addition to the five stages by Kessler (2019) in his upcoming book "Finding Meaning: The Sixth Stage of gief". Kessler describes this stage as finding closure allowing one to heal from their tremendous loss.

\section{August 10, 2019}

Time heals all wounds. 
I do not agree with this saying. I still miss my mom as much as I did the day she died. I will always have an empty place in my heart for her. As I experience new moments in my life, I am still angry that she is not here with me. I will never accept that I have to live my life without her in it.

My dad is alive, and I am grateful. However, I am haunted by the reality that I may lose him to cancer as well. Now, I do everything for my dad. I cook for him. I clean for him. I put up with his ridiculous requests that are impossible to fulfill. My boyfriend tells me constantly that I baby my dad. However, I will never stop because I do not want to feel the regret that I felt when my mom died (Buchbinder; Longhofer, McCue, 2009; Budescu \& Taylor, 2013; Christ \& Christ, 2006; Kitsaras, Goodwin, Allan, Kelly \& Pretty, 2018; McLoyd, 1998)

Today, my life has settled into a new normal. I go to school. I go to work. I spend time with my boyfriend and my friends. I try to get out of the house as much as I can, but sometimes it is hard to be social. People will ask me how I am, and I have to fight the urge to say that I am emotionally broken inside.

It is difficult when people tell me they know how I feel because they lost a grandparent or elderly family member. This is not to say that my loss is worse than anyone else's. However, the loss of a parent is completely life altering, especially at 
a young age. It is impossible to describe the sudden absence of someone so fundamental to who you are (Tilquist et al., 2016).

To my surprise, my mother's death is brought up in my casual conversations with strangers quite frequently. For example, recently I went to a doctor's appointment and I was asked about my lady bug tattoo that I got to honour her. The receptionist, who appeared to be in her late fifties, explained how she knew what I was going through because she lost her mother a few years ago as well. I could not help but think that my mom was around her age when she died. I wish my mom died when I was the receptionist's age. I would have had so much more time with my mom.

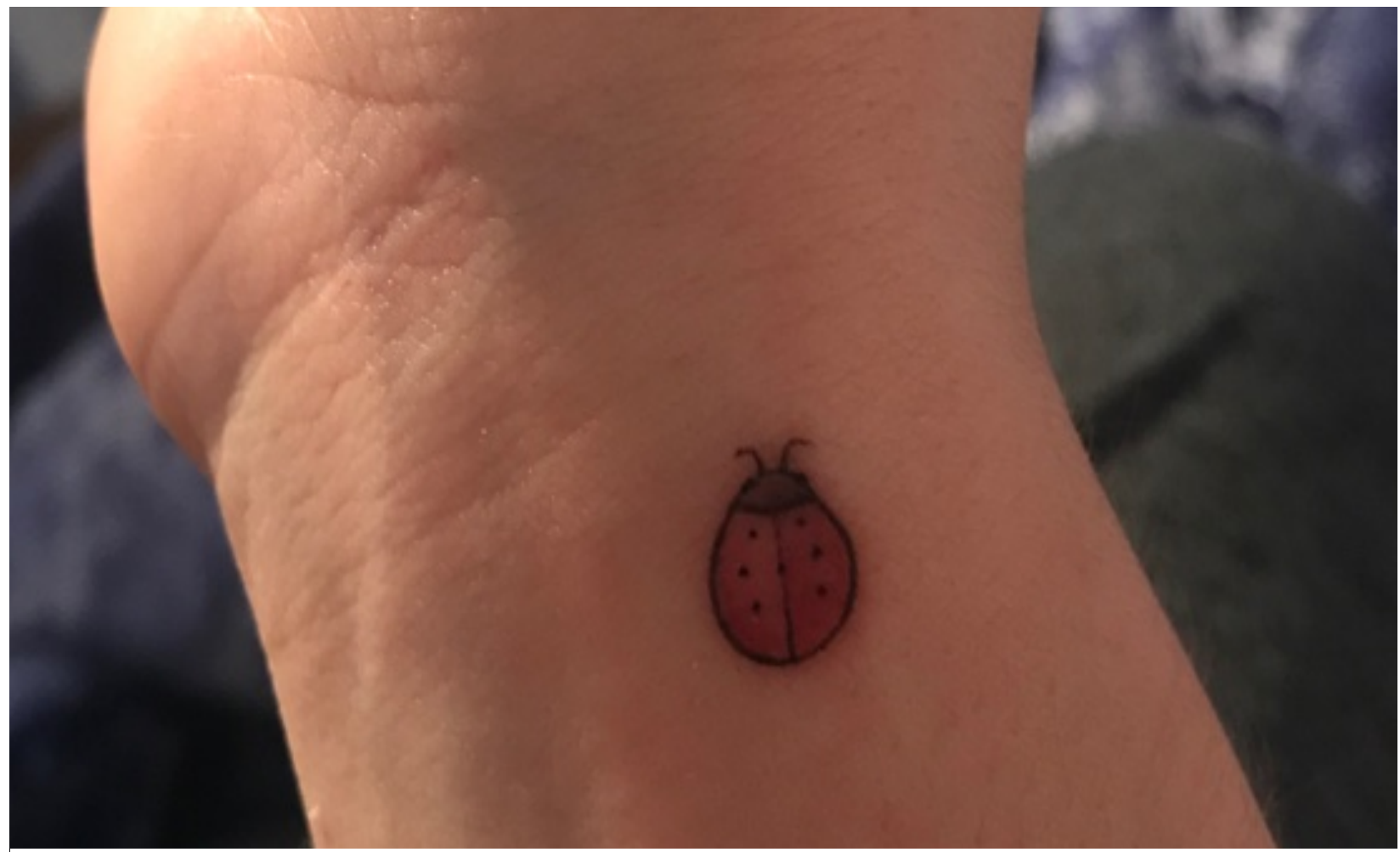

Figure 4: Lady Bug tattoo on my left wrist in honor of my mom. 
I feel like I cannot escape death. Approximately a year after my dad entered remission and was cancer free, my boyfriend's grandmother was diagnosed with terminal cancer. Within a few weeks, she was put on life support. As a nurse, my boyfriend was trusted with important information about the treatment and diagnosis. He was included in conversations with the doctors about when to put an end to the life support. After his family member passed, he was heartbroken because of his loss; however, he seemed much more at peace with the outcome. He did not have regrets. He had accepted early on that death was inevitable and he had to let go.

Approximately eight months after my boyfriend's loss, my sister's father-inlaw was diagnosed with terminal cancer with one year to live. My sister's partner was the only family member in Canada, so he was the primary decision maker throughout his father's treatment process. Although he often did not want to take on the responsibility, I could see that having the knowledge of his father's diagnosis allowed him to have the right mind set and gave him the opportunity to give his father the support he needed. Watching his father deteriorate was devastating, but he had been given as much time as possible to accept that his father would eventually pass away. But it doesn't make it any easier when it happens. 
Through analyzing and exploring a child's experience of bereavement and the parent's decision to inform their child of the diagnosis can often lack a child's rights perspective (Christ, 2000; Harris, 2003; MacPherson, 2005). It seems that parents often feel they are the best decision makers when it comes to decisions involving their children but lack the decision to involve the child (Christ,2000; Fearnley, 2012; Finch \& Gibson, 2009). While acknowledging children are capable of making decisions involving them, as well as capable of providing their own perspective of what is in their best interest, parents often choose to shelter their child in painful or frightening situations (Committee on the Rights of the Child, 2005). Research has shown parents often are the decision makers when choosing to inform their child during the diagnosis process (Christ,2000; Fearnley, 2012; Finch \& Gibson, 2009). Parents often choose to keep their child uninformed, in the 'best interest of the child', without involving the child in the decision-making process (Buchwald, Delmar, \& Schantz-Laursen, 2012). It is common for families to identify adult concerns as situations that should not involve children as they are vulnerable and incapable of appropriately judging their own abilities to cope with circumstances (Christ \& Christ, 2006). However, once the ill-parent loses their independence, the child is frequently involved to help provide care and comfort (Christ, 2006; Fearnley, 2012; Neal \& Neal, 2013). When determining what age is most appropriate to be informed, medical professionals often are reluctant to provide answers as they are unaware of the child's development and if they are capable of handling the situation (Arber \& Odelius, 2018). Recommendations and support should be provided to families in ways of supporting parents in informing their child of the diagnosis. For example, parents can be provided 
with resources to help them understand age appropriate ways to involve their children in difficult conversations about illness and loss.

When considering why a parent may be reluctant to inform their child, common feelings of wanting to keep the child away from feeling fear or pain were found (Harris, 2003; Tilquist et al., 2016). In an effort to normalize the idea of children being involved in matters involving them, the UNCRC developed 54 articles that address the rights of a child (Committee on the Rights of the Child, 2005). The UNCRC acknowledges children's basic human rights, fighting for children to be heard, and their feelings to be involved in the decision making in all matters that involve them (Committee on the Rights of the Child, 2005). From my own experience, I was unfamiliar with children having their own rights and believed parents had the right to make decisions on a child's behalf no matter the circumstance. When I learned about the UNCRC and developed an understanding of children's rights, I recognized that children can and should have a voice in matters that concern them. From that point, my passion to share with others the rights of a child to be involved and a parent's duty to act in the best interest of their child motivated me to share my story. For me, I do not think that knowing my rights would have made a difference in my experience due to my dad's parenting style, however, I believe parents and children informed of the UNCRC can change their views and act in a manner suitable to the child's development.

My parents chose to protect my sister and I from pain. But through that they unintentionally caused me more grief, frustration, and guilt. I find children are rather thrown into situations instead of slowly guided. What I 
mean by this is, similar to my experience, my mom told my sister and I about her diagnosis only because her surgery was scheduled. Providing her and my dad months to get used to their new reality and us... days. I believe if I was informed from the beginning of the diagnosis, I would have had less guilt following my mom's death. Similarly, I did everything I could have possibly done for my dad, and the results ended positively. I always question, would things have turned out different if I knew the whole truth from the beginning, do I even know the truth now?

It seems if parents were aware of their child's ability to process the information and the positive outcomes associated to being involved, they may choose to inform their child early on in the diagnosis. Gates and Lackey (1998) found when children are involved in the caring for the ill parent, a greater attachment is formed. However, as previously mentioned, without information regarding the diagnosis and being involved in order to understand the situation, children may experience anger and frustration at having to take on these tasks and may feel left out (Gates \& Lackey, 1998). When children are informed and involved in caring for their ill parent, children tend to feel greater attachment to their ill parent and less guilt and resentment from going to appointments and completing extra tasks (Gates \& Lackey, 1998). Medical professionals should assist in open discussions to become accustomed and open to the idea of slowly involving the child in the diagnosis process to assist their understanding and decrease their assumptions of the situation (Fearnley, 2012; MacPherson, 2005; Milberg \& Friedrichsen, 2017). 
Along with medical professionals, early childhood educators (ECE) and teachers are equipped to help children and parents handle stressful, challenging, and life changing events. None of the research reviewed includes an ECE's perspective in providing assistance to children experiencing a parent battling a terminal illness. However, using my experience as an ECE, I will provide instances where their knowledge can assist families and children in the classroom. To begin, when notified of the parent's illness, educators can check in with children daily to encourage them to share their thoughts and feelings. Children will express feelings of sadness, anger, and fear, all which are expected; however, it is important to help educate them to eliminate misconceptions. At the same time, educators can have open conversations with parents about their child's understanding of the illness, and their development and interactions at school. Educators can also recommend books to parents to help teach children challenging topics with an item they enjoy. On the other hand, educators can recommend families to speak to a social worker to help with the child's ability to cope with their new reality. Social workers are able to build relationships with children and families to help create open honest conversations (Winter et al., 2017). By doing so, they are able to understand their concerns, fears, and worries. A social worker will help work through their fears using intervention strategies and can work with the family over time to ensure their coping is managed before, during, and after the loss of a loved one (Winter et al., 2017).

If parents can become comfortable with children engaging in discussions about the illness and being involved in the entire process, it can create a better outcome for their grief and bereavement after death (Harris, 2003; Finch \& Gibson, 2009; Neal \& Neal, 2013). What is clear in the literature is that children tend to have a greater outcome when 
information is provided throughout the treatment process in a manner suitable to their age and developmental level (Christ \& Christ, 2006; Turner et al., 2007). From my own experience, I had a greater outcome when involved in the treatment as it allowed me to feel helpful and created a closer bond with both my mom and dad. During these challenging times, children are struggling to process the fact that their parent's diagnosis can lead to death, and what the future will look like without them. Spending time with them during this critical period can allow children to ask questions, talk about future plans, and know no matter what their ill parent loves them. Kubler-Ross and Kessler (2015) describe the stages of grief one faces when experiencing the loss of a loved one and identified there in no prescribed order. However, through analyzing my experience of the loss of my mom, I would argue my experience of grief and bereavement happened in the exact order listed. When experiencing a death, it is hard to tell someone when they should be feeling a certain way; this underpins Kubler-Ross and Kessler's model. Grief can cause pain, increased emotions, and feelings that can seem never-ending, resulting in an individual experiencing grief very differently from others. However, research shows grief following the loss of a parent will never go away, but one will learn to live in a new reality and routine as coping begins (Huston, Mcloyd, Mistry, Vandewater, 2002).

Now, my life centres on caring for others. I empathize with my sister and her partner because I know the stress they are under. I try to do whatever I can to make their days easier. Often, I over exert myself. Most of the time, I find I 
have not sat down all day. I realize that I cannot do everything for everyone but keeping busy is all I can do to keep my mind off my pain.

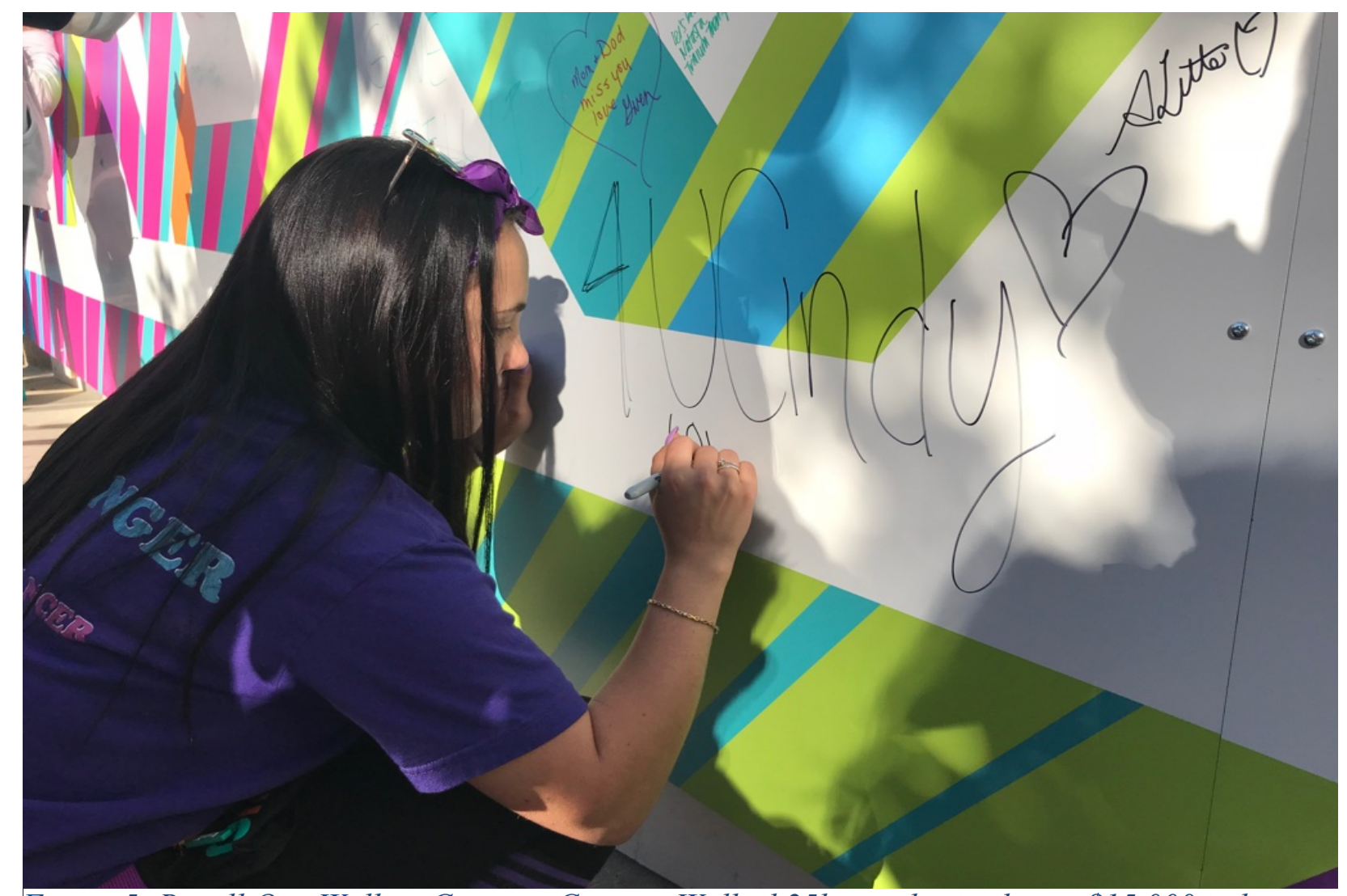

Figure 5: Rexall One Walk to Conquer Cancer: Walked $25 \mathrm{~km}$ and raised over $\$ 15,000$ in honor of my mom.

The loss of my mom will never go away, but I am still thinking of the 'what if's'. Could I have done something different if I was involved earlier? As KublerRoss and Kessler (2005) explained, the stages of grief can occur in no set order. I am still challenged daily when I run into an individual older than myself who still has their mom in their life. Not to say my anger is justifiable, I guess it is related to 
the guilt I still feel, did I tell her how much I appreciated her enough? To date, I am constantly reminding my friends to appreciate their parents and end all arguments, you never know when they can be taken away.

I have come to the conclusion that grief is like chronic pain from a serious injury. The pain will never go away. You learn to live with the pain. 


\section{Appendix A: Consent Form}

\section{Ryerson \\ University}

\section{Ryerson University Consent Agreement}

You are being invited to participate in a research study. Please read this consent form so that you understand what your participation will involve. Before you consent to participate, please ask any questions to be sure you understand what your participation will involve.

\section{TITLE OF RESEARCH PROJECT:}

"You told me when it was too late": An autoethnographic reflection on (not) knowing and bereavement

INVESTIGATORS: This research study is being conducted by Nicole Dulysh and Susan Jagger from The Early Childhood Studies Master's Program at Ryerson University.

This research paper will be reviewed with Ryerson University and published on Ryerson's Database, students and faculty will be granted access.

If you have any questions or concerns about the research, please feel free to contact Nicole Dulysh, at ndulysh@ryerson.ca

\section{PURPOSE OF THE STUDY:}

Children are often left uninvolved in matters termed adult only. However, there is a substantial impact on a child's life when kept uninvolved throughout important aspects. This study will look at my past experience with my parent's diagnoses of cancer and how being informed or uninformed impacts bereavement. This study will be based on my experience through these challenges times but may reflect only family voices through my view. This research is being completed by myself, a graduate study in partial completion of my degree, therefore the results will contribute to my senior thesis.

\section{WHAT PARTICIPATION MEANS:}

As an individual signing this consent form, it is indicating you are aware that your thoughts and feelings may be incorporated through personal experiences throughout the research. As family members, you are providing permission of personal experiences to be shared, as well as, mutual understanding that confidentiality is limited, but names will remain generic (Ex. dad and sister). No data will be collected from these participants.

\section{POTENTIAL BENEFITS:}

I cannot guarantee that you will receive any benefits from participating in this study. However, research is lacking in relation to a child's opinion of whether they should be informed about the diagnosis. Similarly, there is no research on the impact of being informed or uninformed about the terminal illness after the parent's death through the eyes of the child. Therefore, this research will provide an understanding of a parental cancer diagnosis based on a child's opinion. 


\section{WHAT ARE THE POTENTIAL RISKS TO YOU AS A PARTICIPANT?}

The risks associated to this research are medium. As the family members are not involved in the research, but providing consent to speak about personal family matters, and challenges experiences. Therefore, one risk, is a psychological risk factor, which is the possibility of uncomfortable feelings knowing their family experiences are being shared. Therefore, the Tangerine Walk in Centre to receive counselling is available if needed. Second, participant identity is a risk factor, as the research will NOT include family names directly (refer to them as dad and sister), but community members who know the research can indirectly know them or of them. Lastly, reading the research paper post completion and remembering different and challenges times can bring up past emotions. However, the researcher will check in during the research process to ensure consent is continuous. Participates can decline submission of research proposal up until August 1st, 2019. However, once the paper is written and submitted the information cannot be removed

\section{CONFIDENTIALITY:}

There is no information received from anyone besides the researcher. However, family will be identified by dad, sister, etc. In terms of confidentiality, the family members are aware they will be able to be identified by any readers familiar with the researcher. In order to ensure confidentiality is ensured to the maximum, the researcher will not include names in journaling experiences or note taking. The researcher will also ensure their MRP supervisor, Susan Jagger, reviews materials removing any identifying names. Lastly, research and various writing materials will be stored to ensure no access besides the researcher and supervisor.

\section{DATA DISSEMINATION AND DATA STORAGE}

There will not be any data collected by participants, however, the data the researcher recalls will be thematically analysed and used to identify the best outcome for a child during the diagnosis of parental cancer. The data will be stored on a password protected computer including Ryerson password protected Google Drive files if information needs to be shared with the researcher's supervisor. Only the researcher, and MRP Supervisor, Susan Jagger will have access.

The participants will be provided a copy of the research paper ahead of defense. This will be done in person via hard copy. The participants will then have the opportunity to voice any concerns about the content before the research is final. Once the paper is submitted, the information cannot be removed, and this consent agrees to these circumstances.

By agreeing to participate in this research, you are not giving up or waiving any legal right in the event that you are harmed during the research. You are given one week to review the consent form before signing and handing it to the researcher. At that point, the researcher will provide you are copy of the consent and keep the original in a locked cabinet. 
QUESTIONS ABOUT THE STUDY: If you have any questions about the research now, please ask. If you have questions later about the research, you may contact- Nicole Dulysh (email:

ndulysh@,ryerson.ca)

This study has been reviewed by the Ryerson University Research Ethics Board. If you have questions regarding your rights as a participant in this study, please contact:

Research Ethics Board

c/o Office of the Vice President, Research and Innovation

Ryerson University

350 Victoria Street

Toronto, ON M5B 2K3

416-979-5042 -- rebchair@ryerson.ca 
Ryerson

University

RESEARCH TITLE:

"You told me when it was too late": An autoethnographic reflection on (not) knowing and bereavement

\section{CONFIRMATION OF AGREEMENT:}

By signing the consent form, you are agreeing to the researcher sharing family experiences throughout the cancer diagnosis period and feelings associated to these events. You are agreeing to the limited confidentiality associated to the research, and know the researcher is using generic names to keep participants identity hidden to the best of their ability. You are aware there are no benefits to your participation for yourself, however, are aware the research is needed to help determine how being informed or uninformed about a parent's terminal diagnosis influences a child's grieving process. By signing this consent form, you are not waiving any legal rights in the event of research- related harm but agreeing to allowing the researcher to conduct research on past family experiences.

Your signature below indicates that you have read the information in this agreement and have had a chance to ask any questions you have about the study. Your signature also indicates that you agree to allow the researcher to share personal experiences and have been told that you can change your mind and withdraw your consent to participate before the paper is submitted. You have been given a copy of this agreement. You have been told that by signing this consent agreement you are not giving up any of your legal rights.

Name of Participant (please print) 


\section{Appendix B: Ethics Approval}

\section{Research
Ethics Board University}

To: Nicole Dulysh

Re: REB 2019-185: "You told me when it was too late": An auto-ethnographic reflection on (not) knowing and bereavement

Date: June 6, 2019

\section{Dear Nicole Dulysh,}

The review of your protocol REB File REB 2019-185 is now complete. The project has been approved for a one year period. Please note that before proceeding with your project, compliance with other required University approvals/certifications, institutional requirements, or governmental authorizations may be required.

This approval may be extended after one year upon request. Please be advised that if the project is not renewed, approval will expire and no more research involving humans may take place. If this is a funded project, access to research funds may also be affected.

Please note that REB approval policies require that you adhere strictly to the protocol as last reviewed by the REB and that any modifications must be approved by the Board before they can be implemented. Adverse or unexpected events must be reported to the REB as soon as possible with an indication from the Principal Investigator as to how, in the view of the Principal Investigator, these events affect the continuation of the protocol.

Finally, if research subjects are in the care of a health facility, at a school, or other institution or community organization, it is the responsibility of the Principal Investigator to ensure that the ethical guidelines and approvals of those facilities or institutions are obtained and filed with the REB prior to the initiation of any research.

Please quote your REB file number (REB 2019-185) on future correspondence.

Congratulations and best of luck in conducting your research.

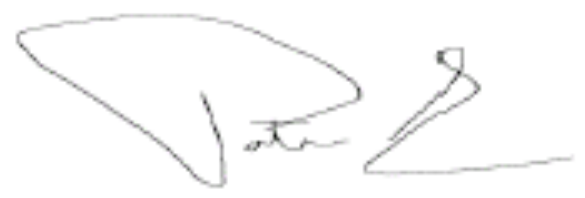

Dr. Patrizia Albanese, $\mathrm{PhD}$

Chair, Ryerson University Research Ethics Board

The Following protocol attachments have been reviewed and approved. 
- MRP Ethics References.docx (submitted on: 03 May 2019)

- REB Consent.docx (submitted on: 05 May 2019)

- REB Consent V. 2 05.05.19.docx (submitted on: 05 Jun 2019)

- REB Resubmission 2019-185.docx (submitted on: 05 Jun 2019)

If any changes are made to the attached document throughout the course of the research, an amendment MUST be submitted to, and subsequently approved by the REB. 
Appendix C: Ethics Certificate

\section{PANEL ON}

RESEARCH ETHICS

\section{TCPS 2: CORE}

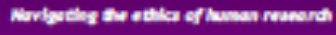

\section{Certificate of Completion}

This document certifies that

Nicole Dulysh

has completed the Tri-Council Policy Statement:

Ethical Conduct for Research Involving Humans

Course on Research Ethics (TCPS 2: CORE)

Date of lssue: 17 September, 2018 


\section{References}

Adams, T. E., Bochner, A. P., \& Ellis, C. (2011). Autoethnography: An overview. Forum: Qualitative Social Research, 12(1), 1-19

American Society of Clinical Oncology (2019). Navigating cancer. Retrieved from https://www.cancer.net/navigating-cancer-care/how-cancer-treated

Arber, A., \& Odelius, A. (2018). Experiences of oncology and palliative care nurses when supporting parents who have cancer and dependent children. Cancer Nursing, 41(3), 248254. doi:10.1097/NCC.0000000000000491

Beale, E. A., Sivesind, D., \& Bruera, E. (2004). Parents dying of cancer and their children. Palliative and Supportive Care, 2, 387-393.

Biank, N. M., \& Werner-Lin, A. (2011). Growing up with grief: Revisiting the death of a parent over the life course. OMEGA - Journal of Death and Dying, 63(3), 271-290. doi:10.2190/OM.63.3.e

Board on Children, Youth, and Families (U.S.), Children, Committee on Supporting the Parents of Young, Breiner, H., Ford, M. A., Gadsden, V. L., Division of Behavioral and Social Sciences and Education, ... Committee on Supporting the Parents of Young Children. (2016). Parenting matters: Supporting parents of children ages 0-8. Washington, DC. The National Academies Press. doi:10.17226/21868

Bretherton, I. (1992). The origins of attachment theory: John Bowlby and Mary Ainsworth. Developmental Psychology, 28(5), 759-775. doi:10.1037//0012-1649.28.5.75

Buchbinder, M., Longhofer, J., \& Mccue, K. (2009). Family routines and rituals when a parent has cancer. Families, Systems, \& Health,27(3), 213-227. doi:10.1037/a0017005 
Buchwald, D., Delmar, C., \& Schantz-Laursen, B. (2012). How children handle life when their mother or father is seriously ill and dying. Scandinavian Journal of Caring Sciences, 26(2), 228-235. doi:10.1111/j.1471-6712.2011.00922.x

Budescu, M., \& Taylor, R. D. (2013). Order in the home: Family routines moderate the impact of financial hardship.Journal of Applied Developmental Psychology, 34(2), 63-72. doi:10.1016/j.appdev.2012.11.006

Canadian Coalition for the Rights of Children. (2012). Right in principle, right in practice: Implementation of the Convention on the Rights of the Child in Canada. Ottawa:Canada: Author. Retrieved from https://books-scholarsportalinfo.ezproxy.lib.ryerson.ca/en/read?id=/ebooks/ebooks0/gibson_cppc/2012-0531/1/10545058\#page=1

Canzona, M. R., Love, D., Barrett, R., Henley, J., Bridges, S., Koontz, A., . . \& Daya, S. (2018). "Operating in the dark": Nurses' attempts to help patients and families manage the transition from oncology to comfort care. Journal of Clinical Nursing, 27(21-22), 41584167. doi:10.1111/jocn. 14603

Carrasco, M. Á., Holgado-Tello, F. P., \& Rodriguez Serrano, M. Á. (2015). Intraparental inconsistency: The influence of parenting behaviors on aggression and depression in children. Family Relations, 64(5), 621-634. doi:10.1111/fare.1216.

Christ, G. H. (2000). Healing children's grief: Surviving a parent's death from cancer. Oxford University Press. Retrieved from, http://www.oxfordscholarship.com.ezproxy.lib.ryerson.ca/view/10.1093/acprof:oso/9780 $\underline{195105919.001 .0001 / \text { acprof-9780195105919 }}$ 
Christ, G. H., \& Christ, A. E. (2006). Current approaches to helping children cope with a parent's terminal illness. CA: Cancer Journal for Clinicians, 56(4), 197-212.

Christ, G. H., Siegel, K., \& Sperber, D. (1994). Impact of parental terminal cancer on adolescents. American Journal of Orthopsychiatry, 64(4), 604-613. doi:10.1037/h0079569

Committee on the Rights of the Child. (2005). General Comment No. 7: Implementing child rights in early childhood. United Nations. Retrieved from https://www.refworld.org/docid/460bc5a62.html

Denny, E. and Weckesser, A. (2019). Qualitative research: What it is and what it is not. BJOG: Int J Obstet Gy. 126: 369-369. doi:10.1111/1471-0528.15198

Denshire, S. (2014). On auto-ethnography. Current Sociology, 63(6), 831-850. Retrieved from https://journals-scholarsportal info.ezproxy.lib.ryerson.ca/pdf/00113921/v62i0006/831_oa.xml

Dunn, C. P., \& Burton, B. K. (2017). Ethics of care. Encyclopaedia Britannica. Retrieved from https://www.britannica.com/topic/philosophy

Dwairy, M. A. (2008). Parental inconsistency versus parental authoritarianism: Associations with symptoms of psychological disorders. Journal of Youth and Adolescence, 37, 616-626.

Ellis, C., Adams, T. E., \& Bochner, A. P. (2011). Autoethnography: An overview. Forum : Qualitative Social Research, 12(1)

Fearnley, R. (2010). Death of a parent and the children's experience: Don't ignore the elephant in the room. Journal of Interprofessional Care, 24(4), 450-459. doi:10.3109/13561820903274871 
Fearnley, R. (2012). Supporting children when a parent has a life-threatening illness: The role of the community practitioner. Community Practitioner : The Journal of the Community Practitioners' \& Health Visitors' Association, 85(12), 22-25. Retrieved from, https://search-proquestcom.ezproxy.lib.ryerson.ca/docview/1269463980/fulltext/5DA4FC1E87734A70PQ/1?acc ountid $=13631$

Finch, A., \& Gibson, F. (2009). How do young people find out about their parent's cancer diagnosis: A phenomenological study. European Journal of Oncology Nursing, 13(3), 213-222. doi:10.1016/j.ejon.2009.03.010

Flick, U. (2007). Qualitative Research kit: Designing qualitative research. London: SAGE Publications, Ltd. doi: 10.4135/9781849208826

Gates, M. F., \& Lackey, N. R. (1998). Youngsters caring for adults with cancer. Image -- the Journal of Nursing Scholarship, 30(1), 11-15.

Government of Canada (2017). The TCPS 2 Tutorial Course on Research Ethics. Panel on Research Ethics. Retrieved from, http://www.pre.ethics.gc.ca/eng/policypolitique/initiatives/tcps2-eptc2/Default/

Harris, C. A. (2003). Breast cancer in the family context: Predictors and consequences of communication about cancer with the patient's children in relation to a family systems theory model. Retrieved from, https://search-proquestcom.ezproxy.lib.ryerson.ca/docview/305346911?pq-origsite=summon

Hersh, E. (2019). Cancer remission: What you need to know. Retrieved from https://www.healthline.com/health/cancer/cancer-remission 
Howell, K. H., Barrett-Becker, E. P., Burnside, A. N., Wamser-Nanney, R., Layne, C. M., \& Kaplow, J. B. (2016). Children facing parental cancer versus parental death: The buffering effects of positive parenting and emotional expression. Journal of Child and Family Studies, 25(1), 152-164. doi:10.1007/s10826-015-0198-3

Jantzer, V., Groß, J., Stute, F., Parzer, P., Brunner, R., Willig, K., . . . \& Resch, F. (2013). Risk behaviors and externalizing behaviors in adolescents dealing with parental cancer-a controlled longitudinal study. Psycho-oncology, 22(11), 2611-2616. doi:10.1002/pon.3327

Jenson, E. W., James, S. A., Boyce, W. T., \& Hartnett, S. A. (1983). The family routines inventory: Development and validation. Social Science \& Medicine, 17, 201-211.

Johnson, J. (1999). Keys to helping children deal with death and grief. Barron's Educational Series. Retrieved from http://web.b.ebscohost.com.ezproxy.lib.ryerson.ca/ehost/detail/detail?vid=0\&sid=e3af18d 7-b7c8-4ada-af7b-50cf9852d698\%40pdc-vsessmgr06\&bdata=JnNpdGU9ZWhvc3QtbG12ZQ\%3d\%3d\#AN=52223\&db=nlebk Johnson, L., Torres, C., Sykes, A., Gibson, D. V., \& Baker, J. N. (2017). The bereavement experience of adolescents and early young adults with cancer: Peer and parental loss due to death is associated with increased risk of adverse psychological outcomes. PLoS One, 12(8) doi:http://dx.doi.org.ezproxy.lib.ryerson.ca/10.1371/journal.pone.0181024

Kitsaras, G., Goodwin, M., Allan, J., Kelly, M. P., \& Pretty, I. A. (2018). Bedtime routines child wellbeing \& development. BMC Public Health, 18, 1-12 doi:http://dx.doi.org.ezproxy.lib.ryerson.ca/10.1186/s12889-018-5290-3

Kubler-Ross, E., \& Kessler, D. (2005). On grief and grieving. New York: Scribners. 
Leavy, P. (2017). Research design: Quantitative, qualitative, mixed methods, arts-based, and community based participatiory approaches. New York: Guilford Press.

Leedham, B., \& Meyerowitz, B. E. (1999). Responses to parental cancer: A clinical perspective. Journal of Clinical Psychology in Medical Settings, 6(4), 441-461. Retrieved from http://link.springer.com.subzero.lib.uoguelph.ca/content/pdf/10.1023\%2FA\%3A1026228 000254.pdf

MacPherson, C. (2005). Telling children their ill parent is dying: A study of the factors influencing the well parent. Mortality, 10(2), 113-126. doi:10.1080/13576270500102872

MacPherson, C. (2018). Supporting parents and children prior to parental death in an NHS setting. Bereavement Care, 37(2), 67-73. doi:10.1080/02682621.2018.1493639

McLoyd, V. C. (1998). Socioeconomic disadvantage and child development. American Psychologist, 53, 185-204.

McPhail, C., Dwyer, J. J. M., Hanemaayer, R., \& Preyde, M. (2017). The experience of parental cancer among emerging adult university students. Journal of Psychosocial Oncology, 35(2), 202-219. doi:10.1080/07347332.2016.1275918

Melcher, U., Sandell, R., \& Henriksson, A. (2015). Maintaining everyday life in a family with a dying parent: Teenagers' experiences of adapting to responsibility. Palliative $\&$ Supportive Care, 13(6), 1595.-1601 doi:10.1017/S1478951515000085

Merriam-Webster (2019). Care. Retrieved from, https://www.merriamwebster.com/dictionary/care

Milberg, A., \& Friedrichsen, M. (2017). Attachment figures when death is approaching: A study applying attachment theory to adult patients' and family members' experiences during palliative home care. Supportive Care in Cancer : Official Journal of the Multinational 
Mistry, R. S., Vandewater, E. A., Huston, A. C., \& Mcloyd, V. C. (2002). Economic well-being and childrens social adjustment: The role of family process in an ethnically diverse lowincome sample. Child Development,73(3), 935-951. doi:10.1111/1467-8624.00448

Neal, J. W., \& Neal, Z. P. (2013). Nested or networked? Future directions for ecological systems theory. Social Development, 22(4), 722-737. doi:10.1111/sode.12018

Paat, Y. (2013). Working with immigrant children and their families: An application of Bronfenbrenner's ecological systems theory. Journal of Human Behavior in the Social Environment, 23(8), 954-966. doi:10.1080/10911359.2013.800007

Porterfield, K., Saldinger, A., \& Cain, A. C. (2004). Meeting the needs of parentally bereaved children: A framework for child-centered parenting. Psychiatry: Interpersonal and Biological Processes, 67(4), 331. Retrived from, https://search-proquestcom.ezproxy.lib.ryerson.ca/docview/220668417?pq-origsite $=$ summon

Rosenheim, E., \& Reicher, R. (1985). Informing children about a parent's terminal illness. Journal of Child Psychology and Psychiatry, and Allied Disciplines, 26(6), 995-998. doi:10.1111/j.1469-7610.1985.tb00613.x

Schlesinger, N. J. (2014). Loss to legacy: The work of mourning early parental death. Psychoanalytic Social Work, 21(1-2), 75-89. doi:10.1080/15228878.2013.859630

St. Pierre, E. A. (2018). Writing post qualitative inquiry. Qualitative Inquiry, 24(9), 603-608. doi:10.1177/1077800417734567

Stone, L. (2018). Nel Noddings: Courageous philosopher and reformer. The High School Journal, 101(2), 100-107. doi:10.1353/hsj.2018.0003 
Stroebe, M., \& Schut, H. (2010). The Dual Process Model of Coping with Bereavement: A decade later. OMEGA - Journal of Death and Dying,61(4), 269-271. doi:10.2190/om.61.4.a

Tillquist, M., Bäckrud, F., \& Rosengren, K. (2016). Dare to ask children as relatives! A qualitative study about female teenagers' experiences of losing a parent to cancer. Home Health Care Management \& Practice, 28(2), 94-100. doi:10.1177/1084822315610104

Trace, C. B. (2016). Ethnomethodology. Journal of Documentation, 72(1), 47-64. doi:10.1108/JD-01-2015-0014

Trusson, D. \& Pilnick, A. (2017). The role of hair loss in cancer identity. Cancer Nursing, 40(2), E9-E16. doi: 10.1097/NCC.0000000000000373.

Tucker, A. R., Sugerman, D., \& Zelov, R. (2013). On belay: Providing connection, support, and empowerment to children who have a parent with cancer. Journal of Experiential Education, 36(2), 93-105. doi:10.1177/1053825913487889

Turner, J., Clavarino, A., Yates, P., Hargraves, M., Connors, V., \& Hausmann, S. (2007). Development of a resource for parents with advanced cancer: What do parents want? Palliative and Supportive Care, 5, 135-145.

Winter, K., Cree, V., Hallett, S., Hadfield, M., Ruch, G., Morrison, F., \& Holland, S. (2017). Exploring communication between social workers, children and young people. British Journal of Social Work, 47(5), 1427-1444. doi:10.1093/bjsw/bcw083 